\title{
Laser Powder Bed Fusion of a Topology Optimized and Surface Textured Rudder Bulb with Lightweight and Drag-Reducing Design
}

\author{
Alessandro Scarpellini ${ }^{1}$, Valentina Finazzi ${ }^{1}{ }^{1}$, Paolo Schito ${ }^{1}$, Arianna Bionda ${ }^{2}$, Andrea Ratti ${ }^{3}$ \\ and Ali Gökhan Demir 1,* \\ 1 Department of Mechanical Engineering, Politecnico di Milano, Via La Masa 1, 20156 Milan, Italy; \\ alessandro1.scarpellini@mail.polimi.it (A.S.); valentina.finazzi@polimi.it (V.F.); paolo.schito@polimi.it (P.S.) \\ 2 Department of Management, Economics and Industrial Engineering, Politecnico di Milano, Via Lambruschini, \\ 4/B, 20156 Milan, Italy; arianna.bionda@polimi.it \\ 3 Department of Design, Politecnico di Milano, Via Giovanni Durando 10, 20158 Milan, Italy; \\ andrea.ratti@polimi.it \\ * Correspondence: aligokhan.demir@polimi.it
}

check for updates

Citation: Scarpellini, A.; Finazzi, V.; Schito, P.; Bionda, A.; Ratti, A.; Demir, A.G. Laser Powder Bed Fusion of a Topology Optimized and Surface Textured Rudder Bulb with Lightweight and Drag-Reducing Design. J. Mar. Sci. Eng. 2021, 9, 1032. https://doi.org/10.3390/ jmse9091032

Academic Editor: Md Jahir Rizvi

Received: 9 July 2021

Accepted: 9 September 2021

Published: 19 September 2021

Publisher's Note: MDPI stays neutra with regard to jurisdictional claims in published maps and institutional affiliations.

Copyright: (c) 2021 by the authors. Licensee MDPI, Basel, Switzerland. This article is an open access article distributed under the terms and conditions of the Creative Commons Attribution (CC BY) license (https:// creativecommons.org/licenses/by/ $4.0 /)$.

\begin{abstract}
This work demonstrates the advantages of using laser powder bed fusion for producing a rudder bulb of a moth class sailing racing boat via laser powder bed fusion (LPBF). The component was designed to reduce weight using an AlSi7Mg0.6 alloy and incorporated a biomimetic surface texture for drag reduction. For the topological optimization, the component was loaded structurally due to foil wing's lift action as well as from the environment due to hydrodynamic resistance. The aim was to minimize core mass while preserving stiffness and the second to benefit from drag reduction capability in terms of passive surface behavior. The external surface texture is inspired by scales of the European sea bass. Both these features were embedded to the component and produced by LPBF in a single run, with the required resolution. Drag reduction was estimated in the order of $1 \%$ for free stream velocity of $2.5 \mathrm{~m} \mathrm{~s}^{-1}$. The production of the final part resulted in limited geometrical error with respect to scales 3D model, with the desired mechanical properties. A reduction in weight of approximately $58 \%$ with respect to original full solid model from 452 to $190 \mathrm{~g}$ was achieved thanks to core topology optimization. Sandblasting was adopted as finishing technique since it was able to improve surface quality while preserving fish scale geometries. The feasibility of producing the biomimetic surfaces and the weight reduction were validated with the produced full-sized component.
\end{abstract}

Keywords: biomimetic design; lightweight structure; computer fluid dynamics; design for additive manufacturing

\section{Introduction}

Metal additive manufacturing (AM) has imposed itself as a competitive alternative with respect to "conventional" production in multiple industrial fields. Supply chain reduction [1], relative design freedom and material waste reduction are only some of the innovations introduced. In the naval field, however, the technology results to be still in early introduction stages. Small to single-unit batches are what is often required, with sensible degree of customization. Lightweight and fluid dynamic resistance reduction are persecuted, involving light materials and optimized shapes, with aim of minimizing operational costs and obtaining more sustainable solutions.

With metal AM, higher degree of design and customization freedom can unlock new levels of product performance, in terms of shape optimization and single client needs in the naval industry. The localized production preserves from transport issues and allows design centers to provide schemes on multiple distributed manufacturing sites. Standardization is required with the aim to validate products and guarantee reliability of the innovative 
production technique. Despite the limited presence of AM in naval sector, these advantages are already being explored [2].

Up to medium size vessels, composite materials lead the manufacturing path, while for large, commercial or tourism cruise vessels, welding, riveting and bolted joins among metal plates are the main approaches for production and assembly. AM technologies can deal with both categories, relying on fused deposition modeling (FDM) techniques for composites [2-4], eliminating any mold need [4,5], while metal techniques such as wire arc additive manufacturing (WAAM) can satisfy plates-based constructions [6,7] and laser powder bed fusion (LPBF), direct energy deposition (DED) or even electron beam melting (EBM) can deal with smaller components, allowing fabrication of relatively complex and curved shapes, unfeasible otherwise in a single production run [8,9].

On metal AM, lightweight is often achieved by means of topology optimization of prior existing geometries [10], as well as the utilization of light metal alloys as could be Alalloys. In this approach, the design of the component is less constrained by fabrication and can be driven by working condition needs. Al-alloys are commonly employed for aerospace and automotive applications requiring lightweight design, where the desired mechanical properties rely on the careful selection of the process parameters [11]. Fluid dynamic behavior can be involved in the design and particularly on surface interaction $[10,12-18]$. As geometrical features can be manufactured directly during the production run of the component, a new generation of products can be obtained, equipped with small-size surface features. These may allow to work with fluid resistance phenomena, that previously had to be accepted as they were, in a functionalization of the surface approach.

In this innovative environment, Politecnico di Milano's Sailing Team (PoliMi Sailing Team) explores the feasibility of using metal AM for the Sustainable Moth Challenge (SuMoth Challenge) hosted by the Foiling Week. It requires teams to design, manufacture and sail a moth class boat according to a common budget-based ruleset, that promotes sustainability and innovation of materials and manufacturing. The moth class boat to be realized is a one-sailor foiling vessel. The research interest over this type of vessel has been concerning the design of passive and active elements to optimize the fluidodynamic behavior against water and air, while the use of textured surfaces and topologically optimized components for weight reduction appear to be neglected [19-21]. In this context, the project also provides several exploitable points using the AM technologies. Even in a relatively small size sailing boat, where most of the manufacturing process is linked to fiber reinforced materials, metal parts play a vital role, often because of impossibility to obtain a reliable assembly of multiple composite parts without them. However, the introduction of metal components must not negatively affect the system, as a local increase of mass may disrupt center of gravity position and so behavior of the boat, as well as the exposed surface should not promote excessive dynamic resistance. The parts to be produced by metal AM processes should address such difficulties. Despite the great potential and the possibility to work in a complete digital environment from design to production, to the authors' knowledge, no previous work in literature addressed different points concerning design, FEM, CFD, and production of a naval component as a whole.

The rudder bulb for the new generation racing boat of PoliMi Sailing Team was the component under study (see Figure 1). Such component is loaded structurally both from the boat and from the fluid environment. The concept is based on the optimization of the main structure of the component for weight reduction as well as to have biomimetic textured surface in contact with water. The combined features were produced via laser powder bed fusion (LPBF) using an Al-alloy. The biomimetic surface texture was inspired by scales of the European sea bass in order to reproduce the hydrodynamic advantage, which results in drag reduction. Both features were designed and tested in a digital environment and later on produced by the AM method. The described concept allows to reduce material waste as well as providing the speed advantage during the race. 


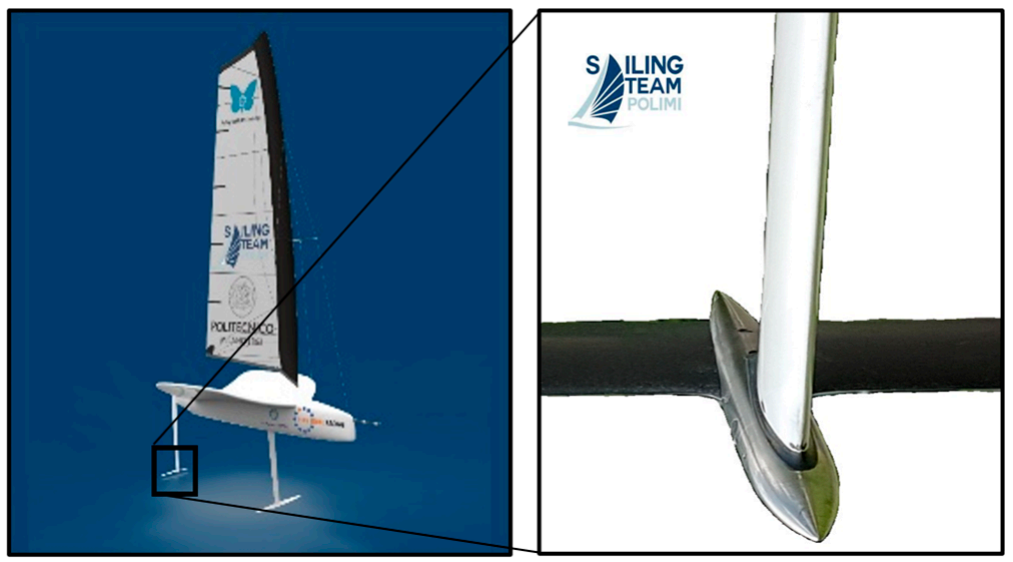

Figure 1. PoliMi Sailing Team rudder bulb concept model, from the team's archive.

Accordingly, the present work aims to demonstrate the potentiality of using metal AM in the naval industry with the selected case study. Hence, this work discusses the design and production stages of a novel lightweight and drag reducing rudder bulb via LPBF. The work shows the finite element modeling (FEM) phases for weight reduction and computer fluid dynamics (CFD) for identifying the advantage of the biomimetic fish scale surfaces. Finally, the component production stages are explained showing high geometrical fidelity with respect to the digital model.

\section{Design of the Rudder Bulb}

\subsection{Design Requirements and Choices}

The PoliMi sailing boat is equipped with two foiling wings, namely the main one, in keel position and the rudder one. The rudder bulb has the aim of structural connection between the rudder vertical and the horizontal wing. This latter is the one that generates approximately $30 \%$ of the lift force required to the moth in order to "fly" above the waterline. The other $70 \%$ is provided by the keel wing. The keel wing has no reason to be displaced with respect to its vertical, as instead is an advantage in the rudder, as allowed by the bulb that in the proposed design, provides regulation in such matter. The resulting spatial translation, along the main boat axis, of the lift force with respect to the rudder vertical below it, allows the sailor to have higher handling, especially while turning, by increasing the span between the keel and the rudder lift force components. The beneficial effect cannot be obtained by displacing all the rudder structure at once because moth class rules impose specific limits in boat body length [22].

The bulb must be realized with a metal alloy, because of the high strength required. The chosen $\mathrm{Al}$ alloy was AlSi7Mg0.6, which is already used in aeronautical applications but novel to LPBF for this field. [23]

A reduction of mass down to $10-30 \%$ of the original internal bulb core volume (design space) is desired, with no excessive loss of stiffness. For the surface, the objective was to investigate the feasibility of using biomimetic surface textures. The feature was evaluated by CFD for drag reduction and its producibility was assessed by the production of the full-scale bulb.

\subsection{Topology Optimization Strategy}

The bulb base model embraces mainly low resistance external shape (i.e., elongated bulb) and foiling wing position regulation (longitudinally). The first is obtained starting from the existing applications as well as PoliMi Sailing Team's experience. The overall longitudinal length of the model is $290 \mathrm{~mm}$. An innovative solution was introduced in order to have the possibility to increase and reduce, during foil set up, the distance between keel lift and rudder lift components. This approach helps to study and find an improved cruising stability when boat is in "flying" condition (raised above water level). 
At the front side, the bulb body must host the rudder vertically (Figure 2a). The joining was made by means of interference fitting, fixed in position with a central bolt. 3D modeling of bulb base geometry was obtained by means of Dassault Systèmes Solidworks environment while Altair Inspire was used for the topology optimization.

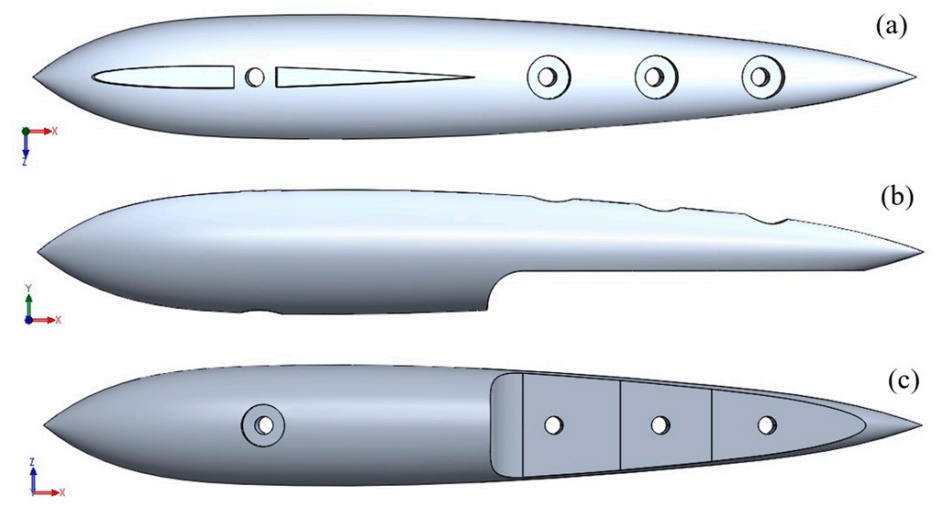

Figure 2. Bulb 3D base model views, (a) top, (b) side, (c) bottom. The overall longitudinal length of the component is $290 \mathrm{~mm}$.

The wing was connected by means of bolts without interference fitting so two bolts at a time are used to constrain the wing in translation and rotation. Hence, two different wing positions (X-wise) could be used. This aspect was considered when defining optimization load cases, as three area subdivisions are sketched in the model to pre-partition the wing connection surface (visible in Figure 2c) for the configuration of the load cases.

Topology optimization was carried out starting from a base model shown in Figure 2a, weighing $452 \mathrm{~g}$ with the same Al-alloy used in LPBF. The model was partitioned geometrically in sub-bodies with the aim to identify the core from all the rest. The core was set as the volume that can be modified by optimization iterations (design space), while the rest, the surrounding "case" or "shell", is the fixed portion, not modifiable and onto which loads are applied. In Figure 3, longitudinal sections of the partitioned model are presented with core (Figure $3 \mathrm{a}$ ) and without core (Figure $3 \mathrm{~b}$ ). Target objective was to reduce the core mass by $10-30 \%$ with respect to the initial design while maximizing the stiffness. The weight performance was evaluated at the FEM level only.

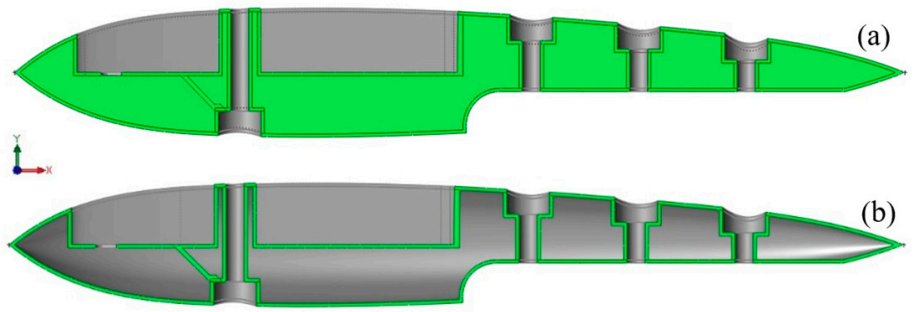

Figure 3. (a) Bulb 3D model partitioning, longitudinal section view; the main green internal portion is the "core" while its contour (shown in green) is part of the "case", (b) case sectioned view, uniform thickness of $1 \mathrm{~mm}$. The overall longitudinal length of the component is $290 \mathrm{~mm}$.

The introduced load cases were obtained considering actions on the bulb structure, mainly transmitted by the down standing wing. The loads were applied contemporarily, and varied according to modeled working condition, while some were common for all load cases. All actions are assumed at maximum criticality of the event (boat speed of about $20 \mathrm{kts}$ or an eventual sailing accident), no extremely rapid impact condition is considered for the optimization. Reasonable impact cases as could be debris impacts or extreme accident were considered to be sufficiently compensated by the minimum safety factor imposed (1.8) with respect to the yield stress (YS). Five optimization runs were conducted as shown in Appendix B. 


\subsection{Definition of the Load Cases}

Prior to the definition of the load cases, all actions on the component structure were identified. Modeling of the actions was made by means of sailing team experience, balance analysis on rudder loads and practical assumptions. The following are the considered actions.

i. Lift force $(L)$ generated on rudder accounts approximately for the $30 \%$ of the overall lift required, however, due to the changing attack angle, the wing may transmit a variable load. To account for this variation, it is considered to have $L$ to be equal to $600 \mathrm{~N}$ for $0^{\circ}$ attack angle, with a direction perpendicular with respect to bulb-wing interface. A magnitude of $400 \mathrm{~N}$ was assumed with inclinations of $\pm 10^{\circ}$ with respect to the interface, to account for magnitude and direction variability load cases. The overall drag force $\left(D_{w}\right)$ due to the relative motion of the wing and the water, transmitted to the bulb is estimated to be approximately $34 \mathrm{~N}$ at $0^{\circ}$ while increasing up to about $50 \mathrm{~N}$ in magnitude for $\pm 10^{\circ}$ attack angle.

ii. Exceptional circumstances may lead to boat roll up to capsize, during such event, or after, while recovering, the wing opposes resistance to fluid, or it may be used as lever for boat recovery. These situations may be emulated on the bulb by means of a torque action $(T)$. The value considered is $6.25 \mathrm{Nm}$. This value simulates a force of $F=12.5 \mathrm{~N}$ applied at $0.5 \mathrm{~m}$, as it is approximately the distance of one wing extremity.

iii. It may happen that the rudder is carried upward due to boat rapid pitch angle change. As a consequence, the wing acts as hydrodynamic resistance, trying to force downward the bulb rear portion with it. The load $\left(P_{c}\right)$ is estimated to be at max $400 \mathrm{~N}$. This load is transmitted to the bulb body by means of wing connecting bolts.

iv. Bulb overall drag force $\left(D_{b}\right)$ at max boat speed condition was estimated to be about $50 \mathrm{~N}$. However, for simplicity no change in magnitude was set when dealing with different attack angle conditions.

v. During the assembly, the compression state imposed by bolts preload should be considered. Rudder vertical bolt preload $\left(P_{v}\right)$ is $60 \mathrm{~N}$ while preloads on wing bolts $\left(P_{w, \text { front }}\right.$ and $\left.P_{w, \text { rear }}\right)$ are $125 \mathrm{~N}$ each.

All the actions are collected in Table 1. Further details are presented in Appendix A.

Table 1. The used load cases in the topological optimization stage.

\begin{tabular}{|c|c|c|c|c|}
\hline Load & Description & Symbol & Unit & Magnitude \\
\hline \multirow{3}{*}{ Lift force } & \multirow{3}{*}{ Rudder wing lift action } & $L\left(0^{\circ}\right)$ & {$[\mathrm{N}]$} & 600 \\
\hline & & $L\left(+10^{\circ}\right)$ & {$[\mathrm{N}]$} & 400 \\
\hline & & $L\left(-10^{\circ}\right)$ & {$[\mathrm{N}]$} & 400 \\
\hline \multirow{3}{*}{ Wing drag force } & \multirow{3}{*}{ Rudder wing motion with respect to water } & $D_{w}\left(0^{\circ}\right)$ & {$[\mathrm{N}]$} & 34 \\
\hline & & $D_{w}\left(+10^{\circ}\right)$ & {$[N]$} & 50 \\
\hline & & $D_{w}\left(-10^{\circ}\right)$ & {$[\mathrm{N}]$} & 50 \\
\hline Capsize torque & Torque due to capsizing of boat & $T$ & {$[\mathrm{Nm}]$} & 6.25 \\
\hline Wing vertical resistance & Resistance to vertical translation of the wing & $P_{c}$ & {$[\mathrm{~N}]$} & 400 \\
\hline Bulb drag force & Bulb motion with respect to water & $D_{b}$ & {$[\mathrm{~N}]$} & 50 \\
\hline Rudder vertical bolt preload & Compression due to assembly & $P_{v}$ & {$[\mathrm{~N}]$} & 60 \\
\hline \multirow{2}{*}{ Wing bolts preloads } & \multirow{2}{*}{ Compression due to assembly } & $P_{w, \text { front }}$ & {$[\mathrm{N}]$} & 125 \\
\hline & & $P_{w, r e a r}$ & {$[\mathrm{~N}]$} & 125 \\
\hline
\end{tabular}

Topological optimization was run by means of successive trials. The followed methodology was based on performing an optimization with stiffness maximization and design space mass decrease targets. The obtained model was then analyzed with respect to all load 
cases and if displacements and safety factors were still acceptable, it was proceeded with a new optimization characterized with a more ambitious core mass reduction with respect to the full core model. All topology optimizations were performed with a symmetry plane requirement with respect to the only symmetry plane of the base model (congruent with section plane of Figure 3), it means that results had to satisfy the symmetry of material spatial distribution with respect to this plane.

Design for laser powder bed fusion rules was also implemented in the optimization work. In order to avoid internal supports, surfaces with angles lower than $45^{\circ}$ with respect to the build platform plane of the LPBF machines should be avoided. The overhang control with $45^{\circ}$ critical angle was not inserted initially to freely optimize the mass with the required rigidity. The optimized geometries were evaluated for overhang regions first. Later, the overhang control was implemented, setting the printing direction and the overhang critical angle.

Minimum thickness of core part was set to be kept above 3-5 mm for all optimizations. It is known from experience that too thin optimized geometry is likely linked to fitting failure when dealing with surface definition. Set material properties are YS, Young modulus, Poisson's ratio and mass density, respectively, at $200 \mathrm{MPa}, 70 \mathrm{GPa}, 0.33$ and $2.68 \mathrm{~g} / \mathrm{cm}^{3}$ using the LPBF as-built properties of the AlSi7Mg0.6 without considering material anisotropy.

\subsection{Biomimetic Texture Design}

Muthuramalingam et al. [24] have studied the hydrodynamic behavior of 3D scanned model-based sea bass scales pattern, reporting a decrease in the overall drag with respect to a surface with no scales. The geometrical model was obtained from a CAD reconstruction tool that used microscopy analysis to assess dimensions directly on fish skin. The fish skin can be represented as a pattern of partially superimposed scales. It was chosen to model each scale as a half circle, linearly growing in thickness and triangular in vertical section. Starting from the midsection (Figure 4 , section A-A), it is a triangle, with base length $l$ (equal to the circle's radius), height $h_{s}$ as the maximum scale thickness and the two angles, $\alpha$ as the "scale angle" and $\beta$.
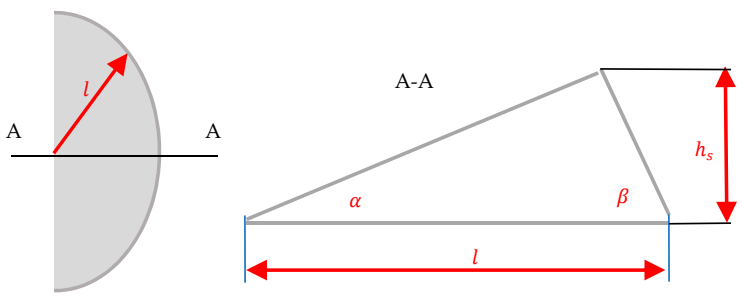

(a)

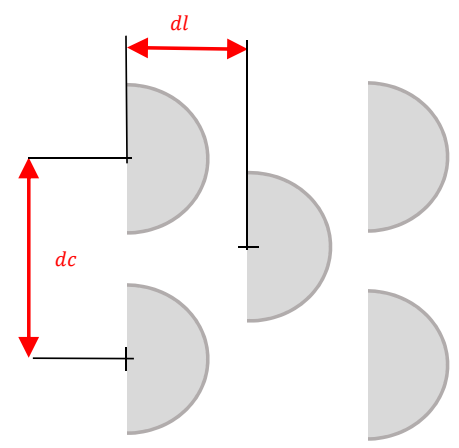

(b)

Figure 4. (a) Scale model geometry and (b) pattern parameters. 
As seen in Figure $4 \mathrm{~b}$, the pattern should allow the scales to be oriented according to the longitudinal axis of the considered carrying body for the growing thickness of the scales themselves and transversally (i.e., circumferentially in case of curvature) with the "scale diameter" (as it corresponds to angle $\alpha$ 's origin position). The longitudinal distance among neighbor-row scales is named $d l$, while among aligned not row-neighboring ones was set to be $2 \times d l$. The transversal spacing among transversally aligned scales is named $d c$, while among not transversally aligned scales the spacing is modeled as $0.5 \times d c$. To determine the single scale geometry, at least three parameters among all mentioned should be set. The chosen ones were $l, h_{s}$ and $\alpha$, while $d l$ and $d c$ are used for the pattern. A surface pattern was determined after a sensitivity analysis, which is not reported here for brevity. The chosen values are listed in Table 2.

Table 2. Chosen scale pattern geometrical parameters.

\begin{tabular}{cccc}
\hline$\alpha$ & $l$ & $d l$ & $d c$ \\
\hline$[\mathrm{deg}]$ & {$[\mathrm{mm}]$} & {$[\mathrm{mm}]$} & {$[\mathrm{mm}]$} \\
\hline 3 & 3 & 0.9 & 6 \\
\hline
\end{tabular}

\subsection{Fluid Dynamic Behavior of the Fish Scale}

Reynolds-averaged Navier-Stokes equations were solved with a k- $\omega$ SST turbulence model using the open-source framework OpenFOAM. The geometry considered for the fluid-dynamic study consists of a flat surface covered with scales: Rhinoceros environment was used to generate the fish scale patterns used for the CFD analysis. A domain sensitivity study, and a mesh independency study was performed, to achieve a reliable numerical model to assess the fluid-dynamic performance of the fish scales. A plate equipped with scales with a dimension of $50 \mathrm{~mm}$ in length and $6 \mathrm{~mm}$ in width was placed in the domain reported in Figure 5. The boundary conditions are cyclic in the transversal direction to emulate an infinitely large plate and has an inlet and an outlet. The mesh selected after the mesh independency study for the numerical computations has a number of cells around 11 million cells, and the calculation was performed on the CFDHub HPC infrastructure at Politecnico di Milano.

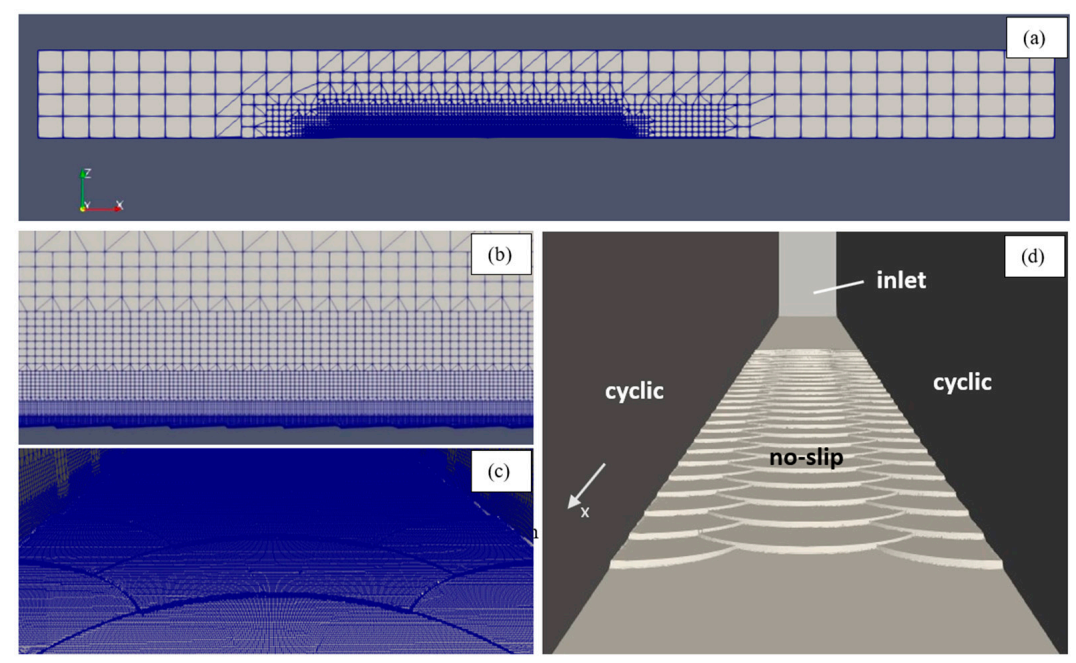

Figure 5. (a) Full domain, lateral view; (b) detail on scale pattern mesh refinement, (c) perspective, (d) boundary conditions.

For comparison the initial design was modeled as a flat surface in the design domain with no fish scales. The drag value was compared to the surface with the scale design determined in Table 2. 


\section{Materials and Experimental Systems}

\subsection{Laser Powder Bed Fusion System}

The full-scale rudder bulb bas produced using a TRUMPF TruPrint 3000 LPBF machine (Ditzingen, Germany). The AlSi7Mg0.6 powder employed had a 20-63 $\mu \mathrm{m}$ grain size (Carpenter Additive, Philadelphia, PA, USA). The powder was produced by means of gas atomization. Process chamber was set to work on Ar inert atmosphere to prevent oxidationrelated issues. The main process parameters are reported as in Table 3. The part density was measured at $99.3 \% \pm 0.2 \%$ by means of optical microscopy. LPBF built processor software used to prepare the building platform in digital environment was Materialize Magics 19 (12/2019-10/2020).

Table 3. Overall volume LPBF process parameters involved.

\begin{tabular}{ccc}
\hline Process Parameters & & Level \\
\hline Chamber oxygen concentration & {$[\%]$} & 0.1 \\
\hline Inert gas type & {$[-]$} & $\mathrm{Ar}$ \\
\hline Shielding gas flow rate & {$[\mathrm{m} / \mathrm{s}]$} & 0.8 \\
\hline Preheating temperature $\left(T_{p h}\right)$ & {$\left[{ }^{\circ} \mathrm{C}\right]$} & 100 \\
\hline Laser spot diameter $\left(d_{s}\right)$ & {$[\mu \mathrm{m}]$} & 100 \\
\hline Layer thickness $(z)$ & {$[\mu \mathrm{m}]$} & 50 \\
\hline Layer scan strategy & {$[-]$} & No pattern \\
\hline Scan direction rot. layer by layer & {$[\mathrm{deg}]$} & 67 \\
\hline Laser power $(P)$ & {$[\mathrm{W}]$} & 345 \\
\hline Scan speed $(v)$ & {$[\mathrm{mm} / \mathrm{s}]$} & 1500 \\
\hline Hatch distance $(h)$ & {$[\mathrm{mm}]$} & 0.10 \\
\hline
\end{tabular}

\subsection{Surface Finishing}

In the study, manual sandblasting was used to improve the surface quality of scale equipped LPBF built surface. The system used to perform the treatment was a Guyson FL600 Blast system equipped with an $8 \mathrm{~mm}$ nozzle diameter, ejecting a 6 bar pressurized mixture of air and abrasive grains. Abrasive grains were dried silica-based sand grains of type BACCHI 510 PLUS.

Sandblasting was performed for approximately $30 \mathrm{~s}$ on all of the surface to be treated, keeping the nozzle at a distance between 10 and $15 \mathrm{~cm}$ from the surface. For the manufactured fish scales, it was observed that small features are preserved and enhanced in quality if the blasting direction is not perpendicular with respect to the surface. An inclination of approximately $45^{\circ}$ was kept with respect to the longitudinal axis of the part.

\subsection{Tensile Test}

Tensile tests were performed on sandblasted tensile specimens to verify the mechanical properties of the build according to ISO 6892. Equipment used to perform the test was an MTS Alliance RT/100 tensile test machine along with an MTS 685.22 Hydraulic Grip Supply (Eden Prairie, MN, USA).

\subsection{Surface Analysis}

The geometrical fidelity of the produced biomimetic surface was evaluated through focus variation microscope (Infinite Focus, Alicona Imaging $\mathrm{GmbH}$, Graz, Austria). Surface height maps were acquired with vertical and lateral resolutions, respectively, at 1 and $15 \mu \mathrm{m}$. The acquisitions were followed by a form removal procedure tool together with a coordinate system adjustment, to center the dataset over the origin of the reference system. To distinguish between surface roughness elements and fish scales geometrical features, a 
cut off wavelength of $0.8 \mathrm{~mm}$ (ISO4287) was used for all roughness measures. This value was smaller than the minimum periodicity length imposed by scale pattern geometries.

Primary profile analysis was used to compare the produced surface profile with the theoretical dimensions. For the roughness measurements, paths of 10-15 mm were selected to comply with the cut-off wavelength. Three paths were selected (Figure 6a) measuring the average roughness $\left(R_{a}\right)$.
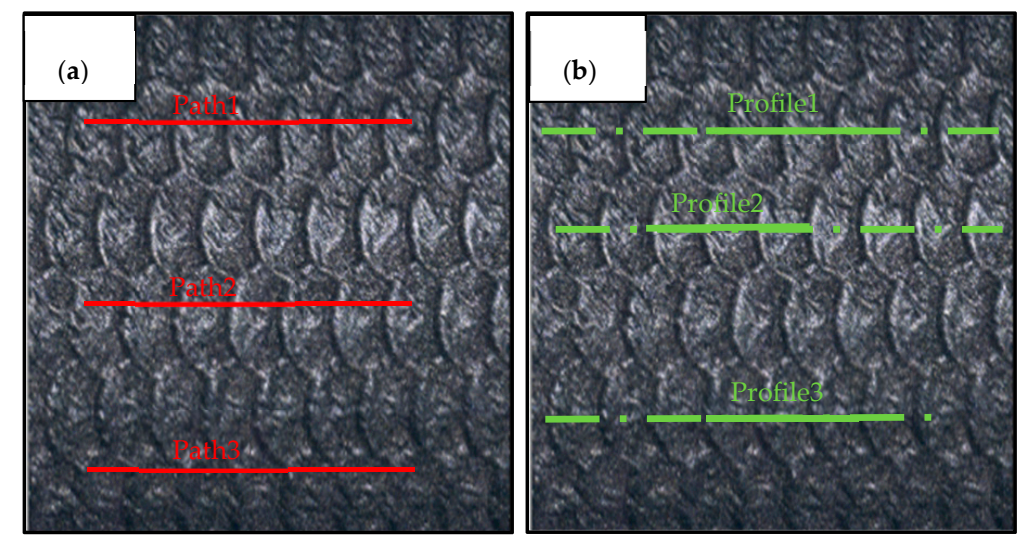

Figure 6. Roughness profile paths example (a), primary profile study paths example (b).

Along with the linear roughness parameters, the areal average roughness $\left(S_{a}\right)$ was measured. Primary profiles analysis was performed choosing three profiles laying on the mid planes of the scale rows (Figure 6b). For each primary profile, the mean peak to valley distance $\left(\Delta p v_{\text {meas }}\right)$ was collected and distance among correspondent scales' points $\left(d l_{s r, i}\right)$ was sampled three times (Figure 7a). The considered distance among correspondent scales' points $\left(d l_{s r}\right.$, meas $)$ for the analyzed profile was the average between the sampled ones. The final considered values for the analyzed scale pattern were then the average results among the three observed profiles. These distances were used to generate a prior assessment of the manufactured scales' quality, comparing with the theoretical distances imposed by the 3D original model, respectively called $\Delta p v_{\text {theo }}$ and $d l_{s r}$, theo (Figure $7 \mathrm{~b}$ ).

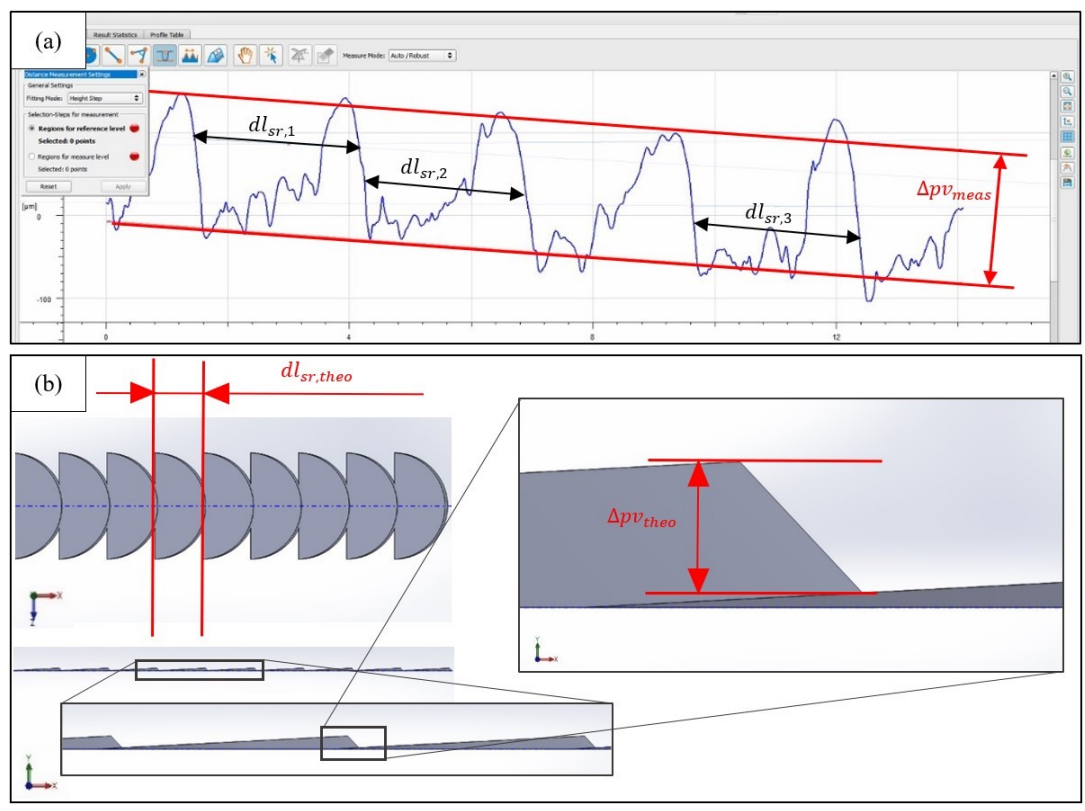

Figure 7. (a) Primary profile mean peak to valley distance (red) and scale to scale correspondent point distance (black) examples, (b) theoretical measures from scale pattern CAD model. 
Each $d l_{s r, i}$ value was taken at a different scale height, preventing eventual nuisance effect in the measure due to a particular sampling position. The "sr" subscript stands for "same row" and it was inserted to distinguish these measures from the previously defined $d l$ parameter, which refers to neighboring different rows, with $d l=0.5 \times d l_{s r}$, theo .

\section{Results and Discussion}

\subsection{Topology Optimized Model}

The successful and sequential topology optimization runs are summarized in Table 4. The observation of mass variability is an indicator of optimization quality. Limited variation (up to $10 \%$ ) is considered to suggest good optimization results, therefore it is possible to consider analyzing the model.

Numerical details are presented in Appendix B.

Table 4. Optimization runs.

\begin{tabular}{|c|c|c|c|c|}
\hline \multirow{2}{*}{ Run Name } & Mass Target & Overhang Control & Core Mass & Core Mass \\
\hline & [\%] wrt. Original & [Yes/No] & {$[\mathrm{kg}]$} & [\%] wrt. Original \\
\hline A & 50 & No & 0.218 & 50 \\
\hline $\mathrm{B}$ & 15 & No & 0.061 & 14 \\
\hline $\mathrm{C}$ & 10 & No & 0.038 & 9 \\
\hline $\mathrm{D}$ & 15 & Yes- $45^{\circ}$ printing orientation & 0.061 & 14 \\
\hline $\mathrm{E}$ & 15 & Yes-90 $90^{\circ}$ printing orientation & 0.059 & 14 \\
\hline
\end{tabular}

Run A was the first optimization performed to assess settings and load case behaviors. Target core mass was set to be reduced down to $50 \%$ of the original value. The result was satisfying in terms of optimization success, but still far from mass reduction target. The minimum safety factor resulting from stress analysis was 3.22, experienced in Working $\left(0^{\circ}, l\right)$ load case condition. The original full model started with a minimum safety factor of 3.97. The high safety factor suggested the possibility to further remove the core material. The geometry of run A was the starting point in run B. Resulting core relative mass, at target level condition was about $13.9 \%$. The model, once tested on the load cases, resulted in minimum safety factor of 3.29. The result suggested that the previous $50 \%$ target was not a limit for structural resistance of the optimized shape. Since B condition was still characterized by a sensible gap from the full model, run $C$ had the aim to explore further mass reduction. Target was set to $10 \%$ and successful run results in 1.82 minimum safety factor (Working $\left(0^{\circ}, l\right)$ load case). However, even if the local high stress did not lead to critical safety factor, maximum displacements reached were too high to be considered acceptable. In particular, bulb geometry would displace in $X$ and $Y$ directions of about 2 and $1.6 \mathrm{~mm}$, respectively. Displacements did not decrease sensibly by increasing the optimization index, not even at index 9 . This condition was not experienced in run B where maximum displacement in any direction is not greater than $0.2 \mathrm{~mm}$. At such point then, mass reduction condition was set to be kept at $15 \%$.

In the final stage of the topological optimization the overhang control was introduced according to the build direction. Run D and run E embraced this need. Run D considered generating a support free core while printing the bulb inclined by $45^{\circ}$ with respect to platform plane with its longitudinal axis and orienting the wing interface surface upward (Figure 8D). Run E employed instead a vertical build of the bulb (Figure 8E). 


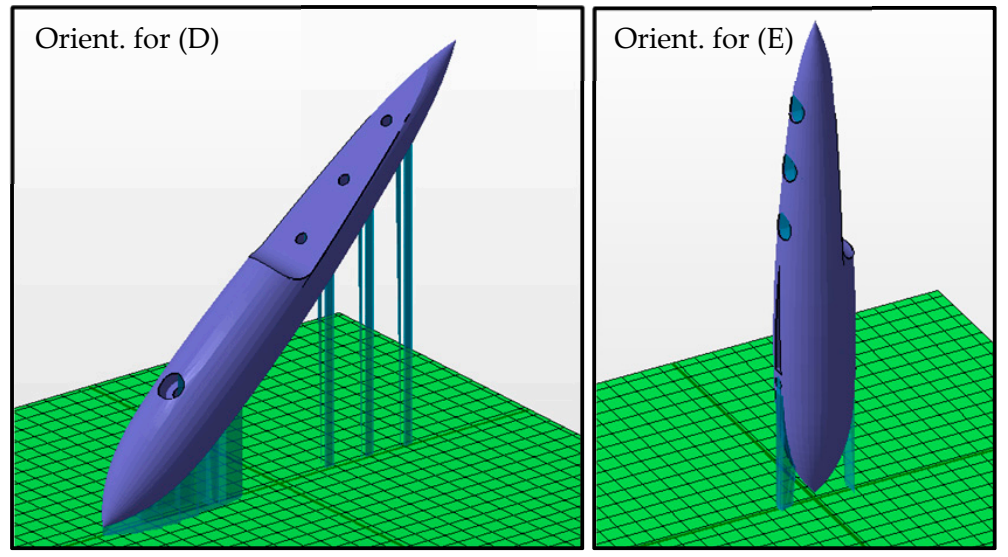

Figure 8. Run $(\mathrm{D}, \mathrm{E})$ with printing orientation emulation in order to account for support free core (overhang critical angle 45). In light blue, the support structures are shown. The overall longitudinal length of the component is $290 \mathrm{~mm}$.

Both result in about $14 \%$ core mass (at target level) but $\mathrm{D}$ minimum safety factor falls to 1.6, while in $\mathrm{E}$ is preserved at 3.18. No excessive displacement concerns results. Since the preferred printing orientation is the one used in $\mathrm{D}$, a more massive version of $\mathrm{D}$ result was analyzed. After a few trials, optimization level was set to index 9; results satisfy the safety factor requirement, resulting in a minimum of 2.46 , while core mass reached $19.7 \%$ with respect to the original core. With the achieved significant reduction of the core mass, the final product mass comprised of the core and shell in the optimized condition was $190 \mathrm{~g}$, corresponding to a $58 \%$ weight reduction.

Such ratio is considered to be acceptable and optimization run D at index 9, named “ $D(9)$ " was set as definitive core geometry. In Figures 9-11, a comparison of $D(9)$ behavior with respect to original model (solid) and "no core" model (null core mass) is reported for the most relevant load cases. No-core condition was tested for comparison to the minimization results achieved with core mass reduction of about $80 \%$. D(9) model achieves similar results as the solid original version while the total lack of core is associated to excessive displacements. Minimum safety factor against yielding results critical only for no core condition, on the majority of load cases. The behavior is related to local stress concentration due to the only presence of the relatively thin case structure bearing loads.
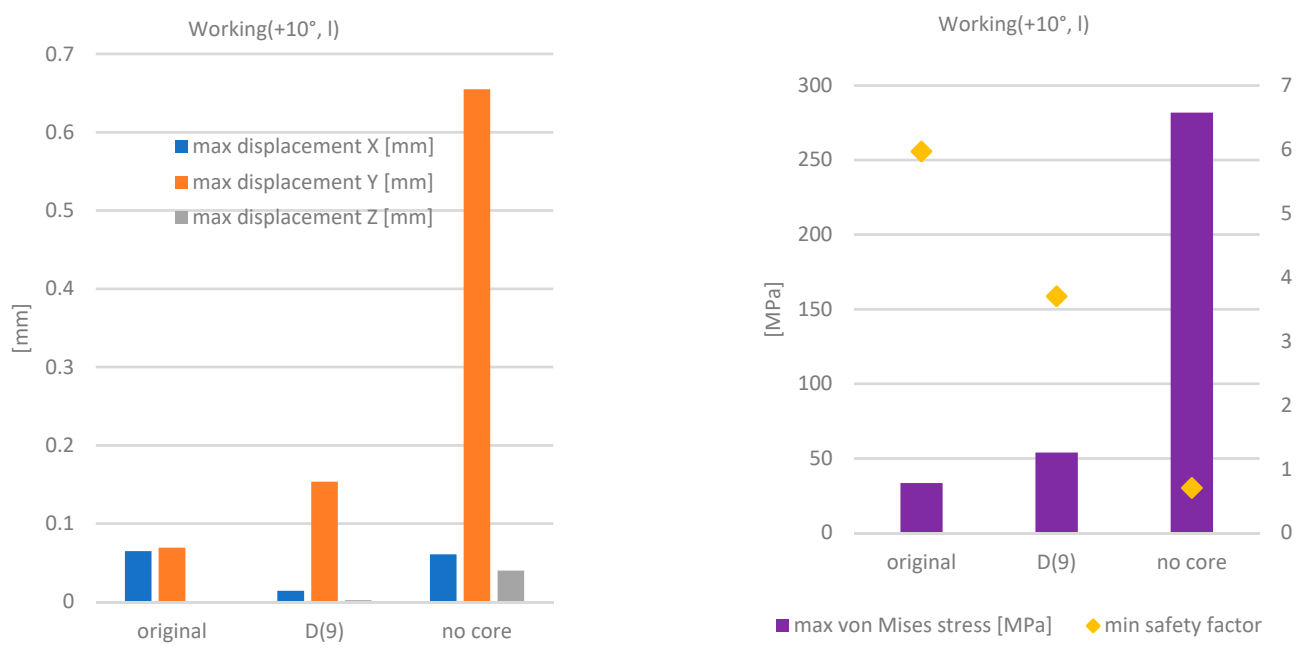

Figure 9. Working $\left(+10^{\circ}, l\right)$ load case analysis results. 

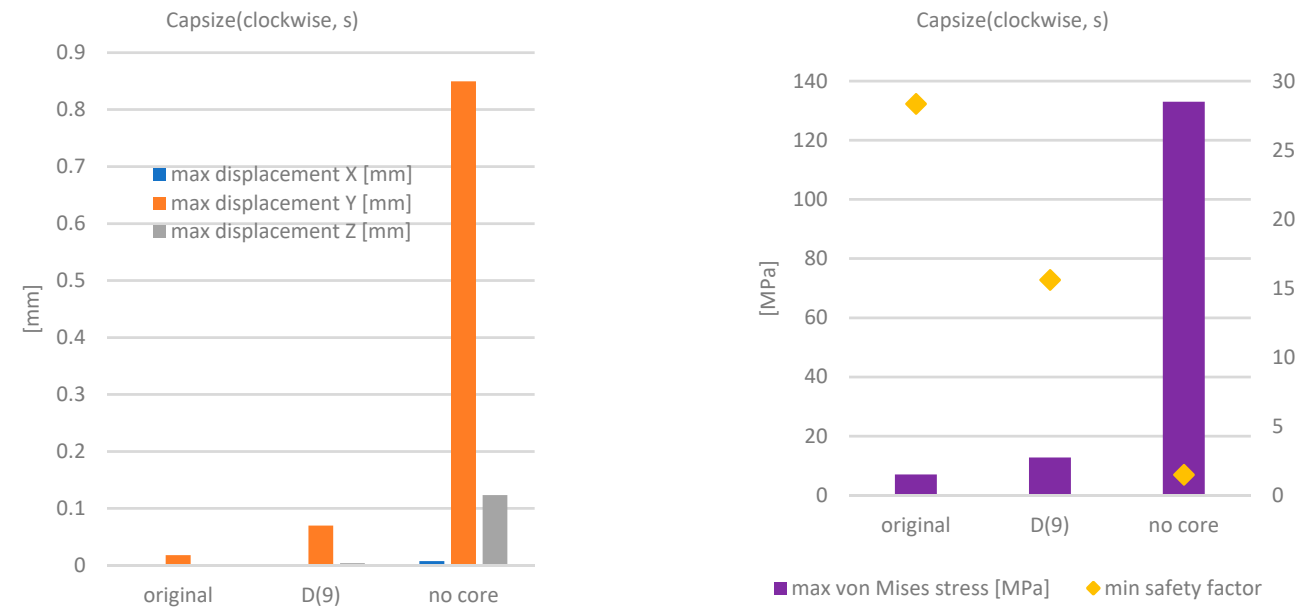

Figure 10. Capsize (clockwise, $s$ ) load case analysis results.
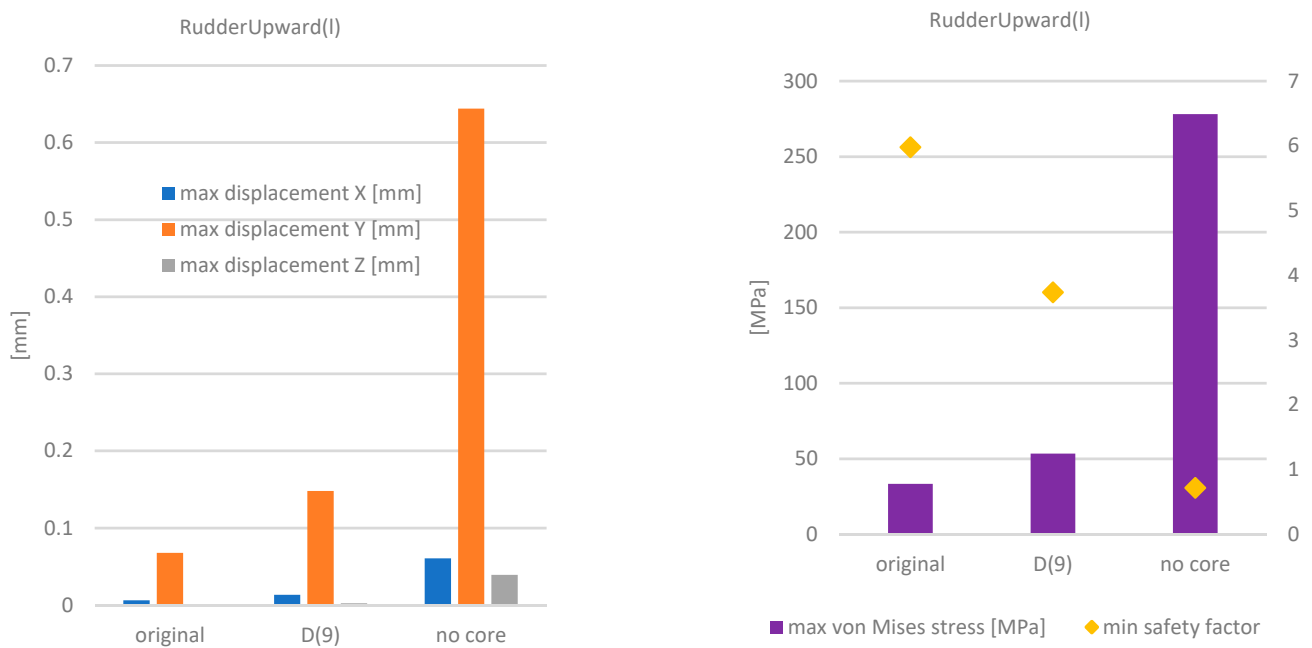

Figure 11. Rudder upward (l) load case analysis results.

Optimized bulb interior definitive shape results as in Figure 12a,b and isolated optimized core geometry is observable in Figure 12c,d. It is also visible the evacuation site for internal powder removal. It is located in a low stress region as well as a hidden and sufficiently covered position in terms of isolation with respect to eventual water penetration since it would be surmounted by rudder vertical encastre extremity.

(a)

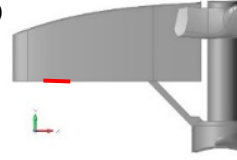

(b)

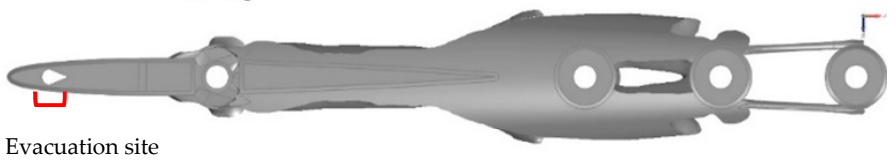

(c)

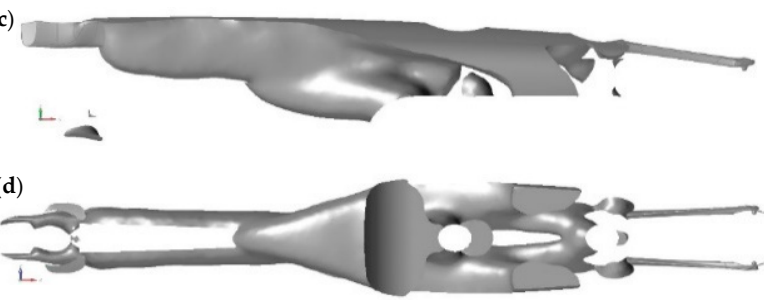

Figure 12. $\mathrm{D}(9)$ core together with interior partitions of bulb; (a) side horizontal view, (b) top horizontal view; while isolated optimized core D(9) shape; (c) side, (d) bottom. The overall longitudinal length of the component is $290 \mathrm{~mm}$.

Stress analysis, on original and optimized shapes, reports localized stresses in the rear edge region on the rudder vertical socket (Figure 13a). The localized stress concentration is present in all load cases and models and it is considered to not represent a material 
resistance critical location since stress levels reached comply in the minimum safety factor (Figure 13c) reached and the local stress state is mainly compressive (Figure 13b); these considerations are valid for all load cases.
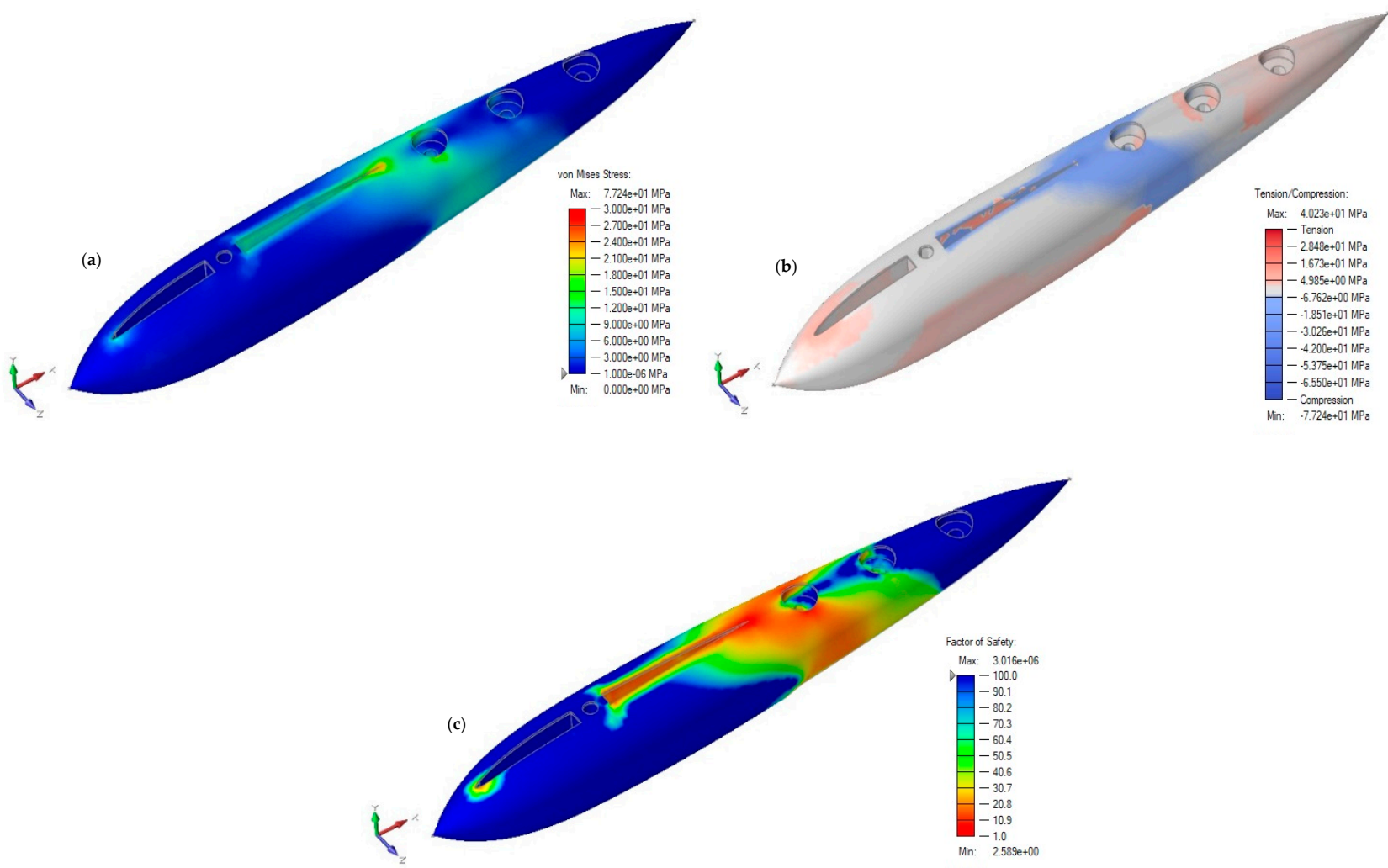

Figure 13. (a) von Mises stress, (b) tension-compression, (c) safety factor (wrt. YS) analyses on Working $\left(0^{\circ}, \mathrm{s}\right)$ load case. The overall longitudinal length of the component is $290 \mathrm{~mm}$.

\subsection{Drag Reduction}

The plate of fixed dimensions is proved to be capable of reaching a reduction of overall drag force of about $1 \%$ at $2.5 \mathrm{~m} / \mathrm{s}$ water speed with respect to a scales-unequipped plate, by means of viscous drag component reduction. Drag force over the test plate is given by the sum of viscous and pressure components along the main stream direction. The viscous component undergoes $19.9 \%$ reduction while the pressure drag force component is increased by about three times due to scale behavior as a series of walls. However, the viscous drag reduction is enough to compensate the pressure component increase and slightly overcome it, determining the reduction of the overall drag force. In Figure 14, the upper view of the tested domain and analogy with the natural behavior on European bass skin by means of speed corridors generation (streaks effect) is linked to viscous drag reduction. The results were found to be coherent with previous research that modeled fish skin [24].

The speed of $20 \mathrm{kts}$ is considered as the highest boat speed. In this condition, loads are of relevant entity for the involved metal component. Moth class vessel speeds may lay around 5-10 kts (2.5-5 m/s). In particular, the ones built for the competition by researchuniversity teams are assumed to sail near such value and have $20 \mathrm{kts}$ as sensibly high limit for boat speed. The speed around $2.5 \mathrm{~m} / \mathrm{s}$ is the most important one, since the boat starts flying and take-off with lower driving force is an advantage when racing. According to the novelty of the work, the presented speed of $2.5 \mathrm{~m} / \mathrm{s}$ is also coherent in terms of possible swimming speed of the involved species and so of the scale geometries involved. While the drag reduction may appear very limited, for the competition purposes such reduction is 
expected to provide an advantage. Beyond the demonstrated results, the work shows that biomimetic surface textures can be further exploited to enhance the sailing performance.

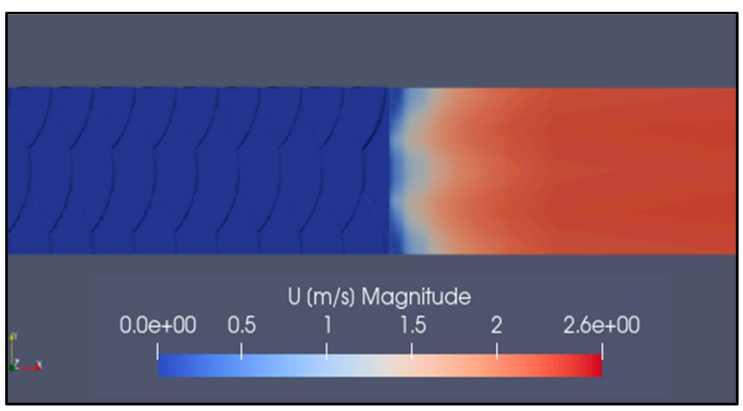

Figure 14. Streaks formation observed on the velocity field at back tested plate.

\subsection{Bulb Production}

Optimized bulb model was at first textured with the chosen scale type. Details are reported in Appendix C. The final bulb geometry was then oriented as optimization case D, with respect to building platform reference plane. With the aim to assess production run mechanical properties, tensile specimens were inserted. As common good practice, control specimens for destructive testing are frequently manufactured together with the final product. This approach increases reliability of product material properties since they can be assumed to be not sensibly distant from the one of control specimens. The whole platform geometries are to be subjected to the same optimized process parameters. Tensile specimens are oriented vertically, horizontally and with same longitudinal bulb axis inclination. This may allow to assess material strength anisotropy among printing orientations. Three specimens are inserted for each orientation. Tensile specimens are supported with software-generated thin geometries (Materialize Magics 19, accessed on September 2020).

Production results in continuative and uninterrupted process. No issues related to evident deformations nor layer scanning errors are reported, with an exception made for horizontally oriented tensile specimens that gained slight curvature with respect to their main axis. Deformation is likely due to high residual stresses achieved during their larger area scanned layers (approximately in correspondence of their mid height). The internal powder evacuation site allowed to remove all powder during the unpacking step, by means of building platform inclination. The built platform is as in Figure 15.

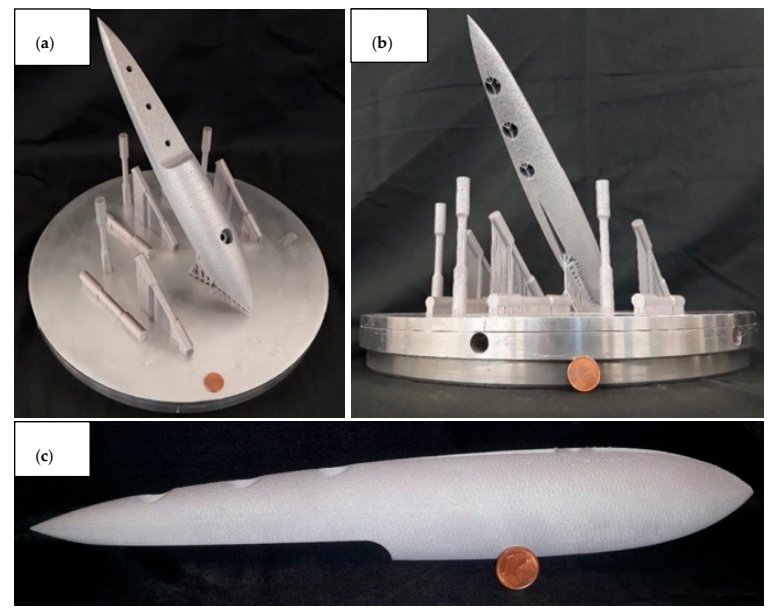

Figure 15. (a) Frontal, (b) back perspectives on built platform, (c) bulb after sandblasting. 


\subsection{Surface and Material Properties}

The analyzed surface was taken in a portion of the bulb with reduced curvature. In Table 5, the resulting roughness and primary profile quality measures are presented. Sandblasting was applied to the bulb external surface. The surface analysis results in improved quality on both roughness and primary profiles. In particular, sandblasting is observed capable of smoothing the highest peaks preserving scale geometrical features.

Table 5. Roughness and primary profiles measures for as built and sandblasted conditions.

\begin{tabular}{ccccccc}
\hline \multirow{2}{*}{ Condition } & $\boldsymbol{R}_{\boldsymbol{a}}$ & $\boldsymbol{S}_{\boldsymbol{a}}$ & $d l_{\boldsymbol{s}, \text { theo }}$ & $d l_{\text {sr, meas }}$ & $\Delta p v_{\text {theo }}$ & $\Delta p v_{\text {meas }}$ \\
\cline { 2 - 7 } & {$[\mu \mathrm{m}]$} & {$[\mu \mathrm{m}]$} & {$[\mu \mathrm{m}]$} & {$[\mu \mathrm{m}]$} & {$[\mu \mathrm{m}]$} & {$[\mu \mathrm{m}]$} \\
\hline As-built & 11.9 & 15.8 & 1800 & 1787 & 89.94 & 99.11 \\
\hline Sandblasted & 7.13 & 9.09 & 1800 & 1888 & 89.94 & 84.29 \\
\hline
\end{tabular}

The final product mass is $220 \mathrm{~g}$, slightly higher than the forecasted one by optimization software of $190 \mathrm{~g}$ (Altair Inspire 19.3, accessed on May 2020). The discrepancy is related to scale pattern geometrical features addition, which have increased the case thickness. Considering the volume occupied by bulb geometry when immersed in water, approximately $114 \mathrm{~cm}^{3}$, the overall force acting on bulb due to simultaneous actions of weight and Archimedes' force, leads to a vertical resultant magnitude of $0.24 \mathrm{~N}$ (oriented as gravity). This means that the bulb is not provided of buoyancy by itself, which is wanted because it would have acted as a destabilizing force in boat rolling behavior, but at same time does not affect boat buoyancy capabilities significantly.

Tensile specimens result in YS of approximately $250 \mathrm{MPa}$ for all printing directions, while UTS and elongation at break (A\%) result smaller for horizontal specimens of about $50 \mathrm{MPa}$ and $3-4 \%$ with respect to the means of $45^{\circ}$ inclined and vertical specimens which both end up in similar values; UTS of about $400 \mathrm{MPa}$ and A\% at 5-6\%. Bulb material mechanical properties can be assumed to be similar to the ones of the specimens. Horizontal specimens performed worse in strength and elongation at break. The reason may lay in residual stresses-caused deformations that could have determined an earlier failure of specimens, due to eventual superimposition of stress states. The bulb is oriented according to $45^{\circ}$ inclined configuration with its main axis. It may be inferred that by the fact that the most relevant load cases would act as bending moment, they encounter the majority of material disposed as such configuration, which appears to lead to acceptable mechanical properties. The rather low elongation at break values observed of the AlSi7Mg0.6 alloy are related to the inherent porosity and the layered structure of the material. While the achieved density is acceptable for most of the applications, the level of porosity (approximately $0.7 \%$ ) can be detrimental for fatigue behavior especially. Mechanical properties of the material depend on the process parameters as well as the machine configuration and the applied heat treatments. The measured properties are comparable to what is reported in the literature [25-30].

Concerning the mechanical properties, AlSi7Mg0.6 can be hardened by an aging treatment. In general practice, a stress-relieving treatment is applied to Al-Si-Mg alloys in order to reduce the thermal stresses generated during the LPBF process [30]. Such treatments generally result in a reduction of the mechanical properties and improve elongation at break compared to the as-built material. Successively aging treatments can be done to improve the mechanical properties and have an isotropic behavior. As a matter of fact, maintaining the high YS and UTS values after an ageing treatment may be difficult and require extensive research. Given the rudder bulb's geometry that does not have extensive transitions from bulky to thin regions, part deformations during the build could be assumed negligible. Without the necessity to apply stress-relieving, further hardening can be possibly avoided. However, the tailored mechanical properties can be beneficial for further improving the topological optimization. 
In this work, isotropic mechanical properties with lower YS and E values during the topological optimization were considered. The resultant mechanical performance of the as-built material was higher. At a level of demonstrating the capability of the metal AM process, the results were sufficient, and no further iterations were carried out with the actual mechanical properties. This can allow to increase the safety factor. Given the fact that the weight reduction was sufficient, and the aim was to maintain the core thickness higher than a limit value, further mass reduction was not also found to be useful.

\section{Conclusions}

This work shows an applied case study where metal additive manufacturing was exploited for the design of a novel rudder hub. The geometrical flexibility of the laser powder bed fusion process was combined with a lightweight Al-alloy to design the component with biomimetic surface design. The main outcomes can be summarized as follows.

- The design step satisfied the mass reduction target. The core mass was reduced by $80.3 \%$ (corresponding to $19.7 \%$ of the original core mass) with acceptable increase in elastic deformations and maximum displacements in the order of $0.1 \mathrm{~mm}$ for the most critical load cases. The final mass composed of the shell and core was reduced by $58 \%$ from 452 to $190 \mathrm{~g}$.

- The biomimetic fish scale surfaces were modeled to understand their fluid dynamic behavior. The results showed improved behavior in terms of viscous drag force component which sees a reduction of about $19.9 \%$.

- The designed rudder hub was manufactured along with specimens to verify the mechanical behavior of the build. The results showed high geometrical fidelity of the scale details, acceptable surface roughness after sandblasting and the desired mechanical properties.

- The results confirm the great potential of using metal AM processes in the naval industry as it combined great geometrical flexibility as well as design and manufacturing in a digital environment. Along with the obtained results, the work shows a framework for the design, manufacturing and verification of the metal AM products for the naval industry with novel features.

In this work, the produced component had relatively small dimensions for the naval sector, while larger parts can be required for other applications. Larger parts can be produced by welding separate additively manufactured parts, which can be also designed for the assembly purposes. The use of topological optimization methods can also be beneficial for designing the component for successive assembly by welding methods. Laser welding can be a viable option for the welding of parts with complex geometries. While Alalloys have overall good weldability with lasers despite their high optical reflectivity [31], the weldability of LPBF produced Al-alloys can be difficult due to very large pore formation observed with these materials [32]. Solid state welding processes such as friction stir welding may be another option, but the complexity of the LPBF parts may require complex weld paths not easily applicable to such processes due to the used tools and applied forces. While this work demonstrated the feasibility of producing biomimetic features and topological optimization together, the final verification of the component performance remains an open issue. The work validated the feasibility of producing the biomimetic surfaces and the weight reduction was verified. On the other hand, the drag reduction estimated with the simulations requires further validation.

Author Contributions: Conceptualization, A.S., P.S. and A.G.D.; data curation, A.S.; formal analysis, A.S. and V.F.; investigation, A.S. and V.F.; methodology, P.S. and A.G.D.; resources, A.G.D.; software, A.S. and P.S.; supervision, P.S., A.B., A.R. and A.G.D.; writing-original draft, A.S. and A.G.D.; writing-review and editing, V.F., P.S., A.B. and A.R. All authors have read and agreed to the published version of the manuscript. 
Funding: The Italian Ministry of Education, University and Research is acknowledged for the support provided through the Project "Department of Excellence LIS4.0—Lightweight and Smart Structures for Industry $4.0^{\prime \prime}$.

Data Availability Statement: The data presented in this study are available on request.

Acknowledgments: The authors are grateful to Trumpf for technical assistance and providing the TruPrint 3000 system.

Conflicts of Interest: The authors declare no conflict of interest.

\section{Appendix A. Load Cases}

Load cases were defined according to the load acting simultaneously on the considered condition. However, exceptions existed for $P_{r, v}, P_{w, \text { front }}$ and $P_{w}$, rear that were inserted uniformly on all load cases, since there is no condition in which they were not present. The capsizing directions were distinguished considering watching the boat from its forward position. Clockwise and counterclockwise directions were considered, and consequently, by being $T$ a resistance action, it will be characterized by opposite direction. Attack angle is named positive if rotation is related to boat forward position to move downward with respect to boat stern height while negative in the opposite case. In Table A1 the distinguished load cases are presented.

Table A1. Considered load cases.

\begin{tabular}{ccc}
\hline Load Case & Description & Loads \\
\hline Working $\left(0^{\circ}\right)$ & Rudder cruising with $0^{\circ}$ wing attack angle & $P_{r, v}, P_{w, \text { front }}, P_{w, \text { rear }}, D_{b}, D_{w}\left(0^{\circ}\right), L\left(0^{\circ}\right)$ \\
\hline Working $\left(+10^{\circ}\right)$ & Rudder cruising with $+10^{\circ}$ wing attack angle & $P_{r, v}, P_{w, \text { front }}, P_{w, \text { rear }}, D_{b}, D_{w}\left(+10^{\circ}\right), L\left(+10^{\circ}\right)$ \\
\hline Working $\left(-10^{\circ}\right)$ & Rudder cruising with $-10^{\circ}$ wing attack angle & $P_{r, v}, P_{w, \text { front }}, P_{w, \text { rear }}, D_{b}, D_{w}\left(-10^{\circ}\right), L\left(-10^{\circ}\right)$ \\
\hline Capsize (clockwise) & $\begin{array}{c}\text { Rudder rotation in correspondence of bulb } \\
\text { longitudinal axis clockwise }\end{array}$ & $P_{r, v}, P_{w, \text { front }}, P_{w, \text { rear }}, T($ counterclockwise $)$ \\
\hline $\begin{array}{c}\text { Capsize } \\
\text { (counterclockwise) }\end{array}$ & $\begin{array}{c}\text { Rudder rotation in correspondence of bulb } \\
\text { longitudinal axis counterclockwise }\end{array}$ & $P_{r, v}, P_{w, \text { front }}, P_{w}$, rear,$T($ clockwise $)$ \\
\hline RudderUpward & Rudder carried upward by boat vertical translation & $P_{r, v}, P_{w, \text { front }}, P_{w, \text { rear }}, P_{c}$ \\
\hline
\end{tabular}

Load cases must also account for position of the wing with respect to the bulb. All loads transmitted by the wing to the bulb by means of bolted connection must be applied in different positions according to the usage of the couple of bolted connections involved. Naming (1), (2) and (3), respectively, the front, middle and rear bolt (Figure A1) and the correspondent interface surface region (Figure 2c), load cases were duplicated as in Table A2, where the utilization of (1) and (2) positions is denoted as " $s$ " (i.e., short configuration) while the utilization of (2) and (3) is denoted as "l" (i.e., long configuration).

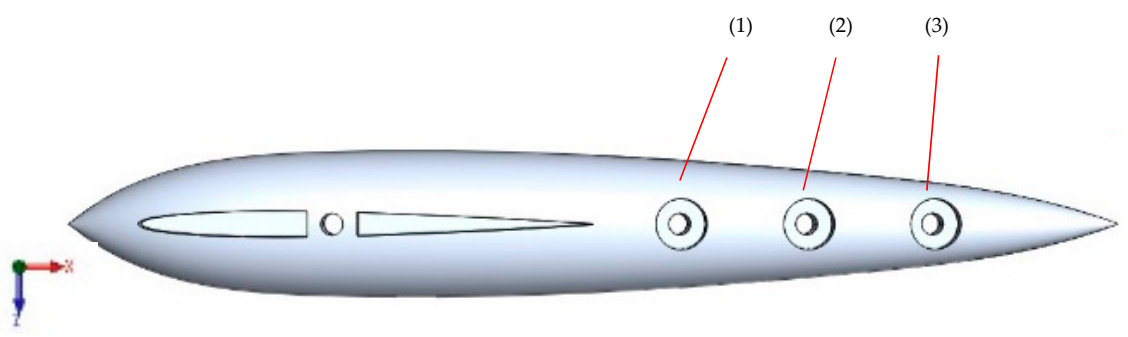

Figure A1. Bolt indexing. (1), (2) and (3), front middle and rear bolt positions. The overall longitudinal length of the component is $290 \mathrm{~mm}$. 
Table A2. Definitive load cases list.

\begin{tabular}{|c|c|c|}
\hline Load Case & Description & Loads \\
\hline Working $\left(0^{\circ}, s\right)$ & $\begin{array}{l}\text { Rudder cruising with } 0^{\circ} \text { wing attack } \\
\text { angle and short configuration }\end{array}$ & $P_{r, v}, P_{w,(1)}, P_{w,(2)}, D_{b}, D_{w}\left(0^{\circ}, s\right), L\left(0^{\circ}, s\right)$ \\
\hline Working $\left(+10^{\circ}, s\right)$ & $\begin{array}{l}\text { Rudder cruising with }+10^{\circ} \text { wing attack } \\
\text { angle and short configuration }\end{array}$ & $P_{r, v}, P_{w,(1)}, P_{w,(2)}, D_{b}, D_{w}\left(+10^{\circ}, s\right), L\left(+10^{\circ}, s\right)$ \\
\hline Working $\left(-10^{\circ}, s\right)$ & $\begin{array}{l}\text { Rudder cruising with }-10^{\circ} \text { wing attack } \\
\text { angle and short configuration }\end{array}$ & $P_{r, v}, P_{w,(1)}, P_{w,(2)}, D_{b}, D_{w}\left(-10^{\circ}, s\right), L\left(-10^{\circ}, s\right)$ \\
\hline Capsize (clockwise, $s$ ) & $\begin{array}{l}\text { Rudder rotation in correspondence of } \\
\text { bulb longitudinal axis clockwise and } \\
\text { short configuration }\end{array}$ & $P_{r, v}, P_{w,(1)}, P_{w,(2)}, T($ counterclockwise,$s)$ \\
\hline Capsize (counterclockwise, $s$ ) & $\begin{array}{l}\text { Rudder rotation in correspondence of } \\
\text { bulb longitudinal axis counterclockwise } \\
\text { and short configuration }\end{array}$ & $P_{r, v}, P_{w,(1)}, P_{w,(2)}, T($ clockwise,$s)$ \\
\hline RudderUpward (s) & $\begin{array}{l}\text { Rudder carried upward by boat vertical } \\
\text { translation and short configuration }\end{array}$ & $P_{r, v}, P_{w,(1)}, P_{w,(2)}, P_{c}(s)$ \\
\hline Working $\left(0^{\circ}, l\right)$ & $\begin{array}{l}\text { Rudder cruising with } 0^{\circ} \text { wing attack } \\
\text { angle and long configuration }\end{array}$ & $P_{r, v}, P_{w,(2)}, P_{w,(3)}, D_{b}, D_{w}\left(0^{\circ}, l\right), L\left(0^{\circ}, l\right)$ \\
\hline Working $\left(+10^{\circ}, l\right)$ & $\begin{array}{l}\text { Rudder cruising with }+10^{\circ} \text { wing attack } \\
\text { angle and long configuration }\end{array}$ & $P_{r, v}, P_{w,(2)}, P_{w,(3)}, D_{b}, D_{w}\left(+10^{\circ}, l\right), L\left(+10^{\circ}, l\right)$ \\
\hline Working $\left(-10^{\circ}, l\right)$ & $\begin{array}{l}\text { Rudder cruising with }-10^{\circ} \text { wing attack } \\
\text { angle and long configuration }\end{array}$ & $P_{r, v}, P_{w,(2)}, P_{w,(3)}, D_{b}, D_{w}\left(-10^{\circ}, l\right), L\left(-10^{\circ}, l\right)$ \\
\hline Capsize (clockwise, $l$ ) & $\begin{array}{l}\text { Rudder rotation in correspondence of } \\
\text { bulb longitudinal axis clockwise and long } \\
\text { configuration }\end{array}$ & $P_{r, v} P_{w,(2)}, P_{w,(3)}, T($ counterclockwise,$l)$ \\
\hline Capsize (counterclockwise, $l$ ) & $\begin{array}{l}\text { Rudder rotation in correspondence of } \\
\text { bulb longitudinal axis counterclockwise } \\
\text { and long configuration }\end{array}$ & $P_{r, v}, P_{w,(2)}, P_{w,(3)}, T($ clockwise,$l)$ \\
\hline RudderUpward $(l)$ & $\begin{array}{l}\text { Rudder carried upward by boat vertical } \\
\text { translation and long configuration }\end{array}$ & $P_{r, v}, P_{w,(2)}, P_{w,(3)}, P_{c}(l)$ \\
\hline
\end{tabular}

All loading conditions rely on the same structural constraints. The bulb was joined by interference fitting with rudder vertical, therefore, bolted constraint was placed in correspondence of the bolt hole, while translation constraints were applied on the surface of the socket.

The "common" loads, that shared the same magnitude and direction as the multiple load cases, were the vertical and wing bolts preloads and bulb drag force. All these were applied as uniformly distributed loads over the local surface partition involved. For drag force, all the external surface was considered.

In the following, some of the load cases are detailed while the constraints are hidden

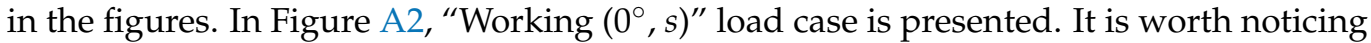
that to comprehend only the first two portions of wing interface surface, both drag and lift, wing caused, actions, are divided equally into two loads each (subscripts (1) and (2) are then added for clarification). Applied loads are not concentrated, they are set as uniformly distributed on the local surface partition of application. 


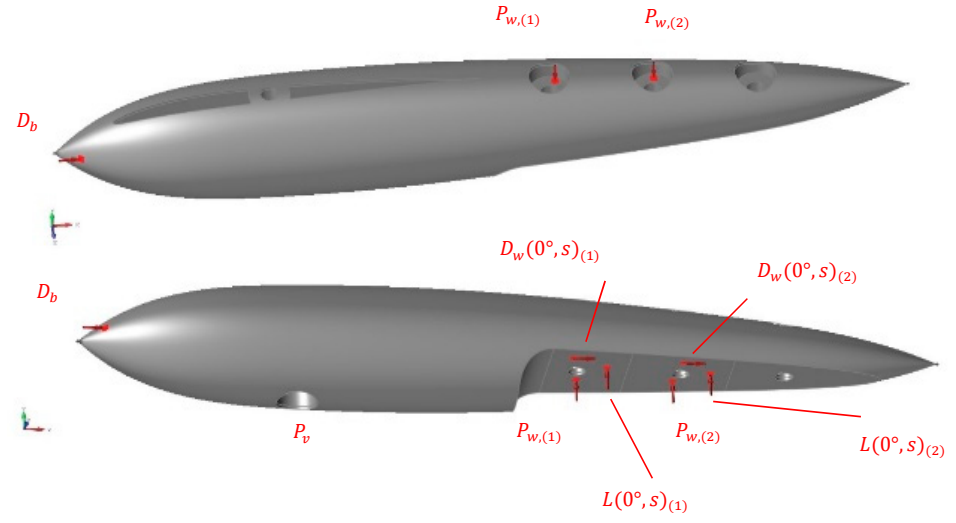

Figure A2. Working $\left(0^{\circ}, s\right)$ load case, constraints are hidden for representation purpose. The overall longitudinal length of the component is $290 \mathrm{~mm}$.

In Figure A3 the load case "Capsize (clockwise, $l$ )" is presented where the torque is obtained by means of concentrated forces applied at $0.25 \mathrm{~m}$ distance with respect to bulb longitudinal axis. Two forces (12.5 $\mathrm{N}$ in magnitude each) are used to comply with the "long" configuration. Application points of forces were connected by means of rigid connectors over the correspondent partition of the interface surface.

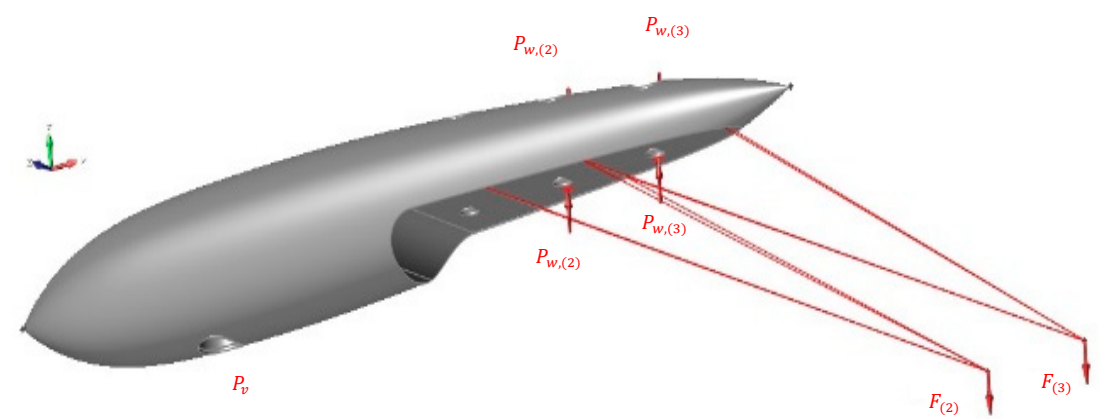

Figure A3. Capsize (clockwise, $l$ ) load case, constraints are hidden for representation. The overall longitudinal length of the component is $290 \mathrm{~mm}$.

In Figure A4 the "RudderUpward (s)" load case is reported. Since the wing tends to resist the carrying action of the rudder, the bulb ends up subjected to $P_{c}(s)$. by means of the bolted junction. Forces were then positioned as the head of the bolt is transmitting the load. Two forces (of equal magnitude, $200 \mathrm{~N}$ ) are used to comply with the "short" configuration.

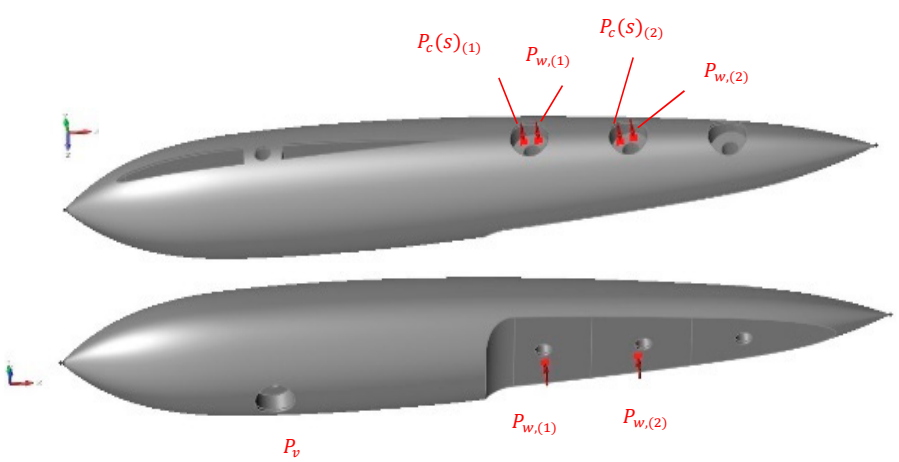

Figure A4. Rudder Upward (s) load case, constraints are hidden for representation purpose. 


\section{Appendix B. Topological Optimization Runs}

The software allows to observe local variation of optimized mass around the target level, in Figure A5, the variations for all the optimization runs, target level corresponds to index 5 in the topology case slider; from 1 to 9 mass increases.

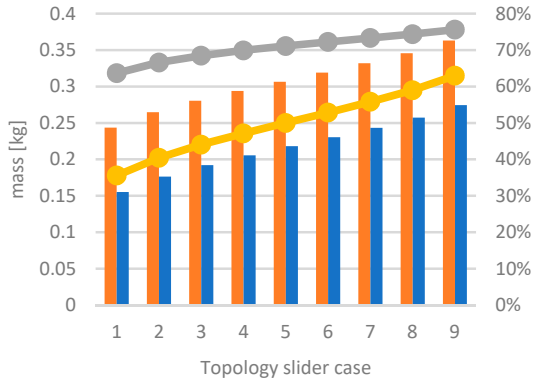

D

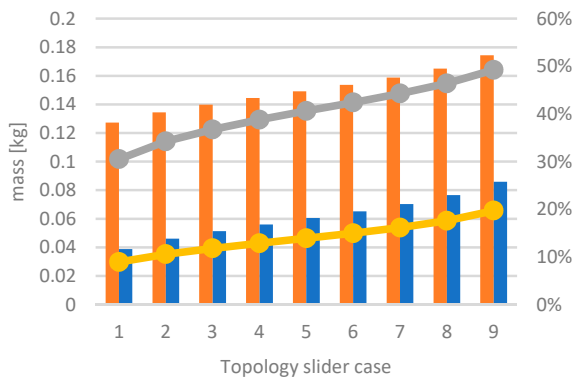

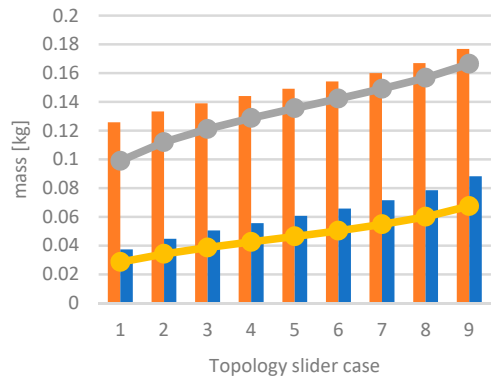

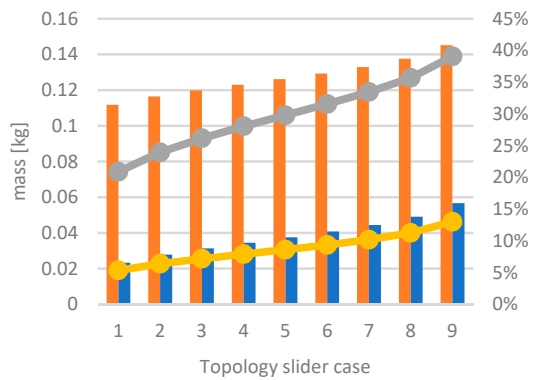

Figure A5. Optimization target neighborhoods. Letters (A-E) corresponds to respective optimization run.

\section{Appendix C. Rudder Bulb Model Design and Support Preparation}

Scale pattern is applied over the bulb case external surface, increasing its thickness according to the local scale height (Figure A6). Bulb structural behavior is considered to be not sensibly affected by thickness increase and at same time by generation of peaks and valleys surface texture (i.e., due to scale pattern profile) that is considered not capable of determining a sensible localized concentration of stress.

The final bulb geometry is then oriented as optimization case D, with respect to building platform reference plane (Figure A7a). The main support structure is designed manually (Figure A7c), since the area to be sustained embraces part of the rudder vertical encastre socket and it is wanted to minimize influence on the local scale pattern geometry. In order to avoid any excessively high platform-part connecting support structures, localized part to part supports are inserted to preserve bolt holes geometry (Figure A7b), since they experience local limited overhang due to product printing orientation. Building orientation is coherent with recoater wear uniformity (recoater comes from $X$ positive direction), supporting needing area minimization as well as production stability principle in terms of thermal energy to be evacuated per scanned layer. The main bulb support structure is designed to be thicker than what structurally required to satisfy thermal evacuation needs since it remains the only direct connected portion with the baseplate. Contact between bulb and main support is limited to avoid any unnecessary joining with scale pattern, by means of contained anchors dimensions and maximum spacing among neighboring anchors (about 2-3 mm). 

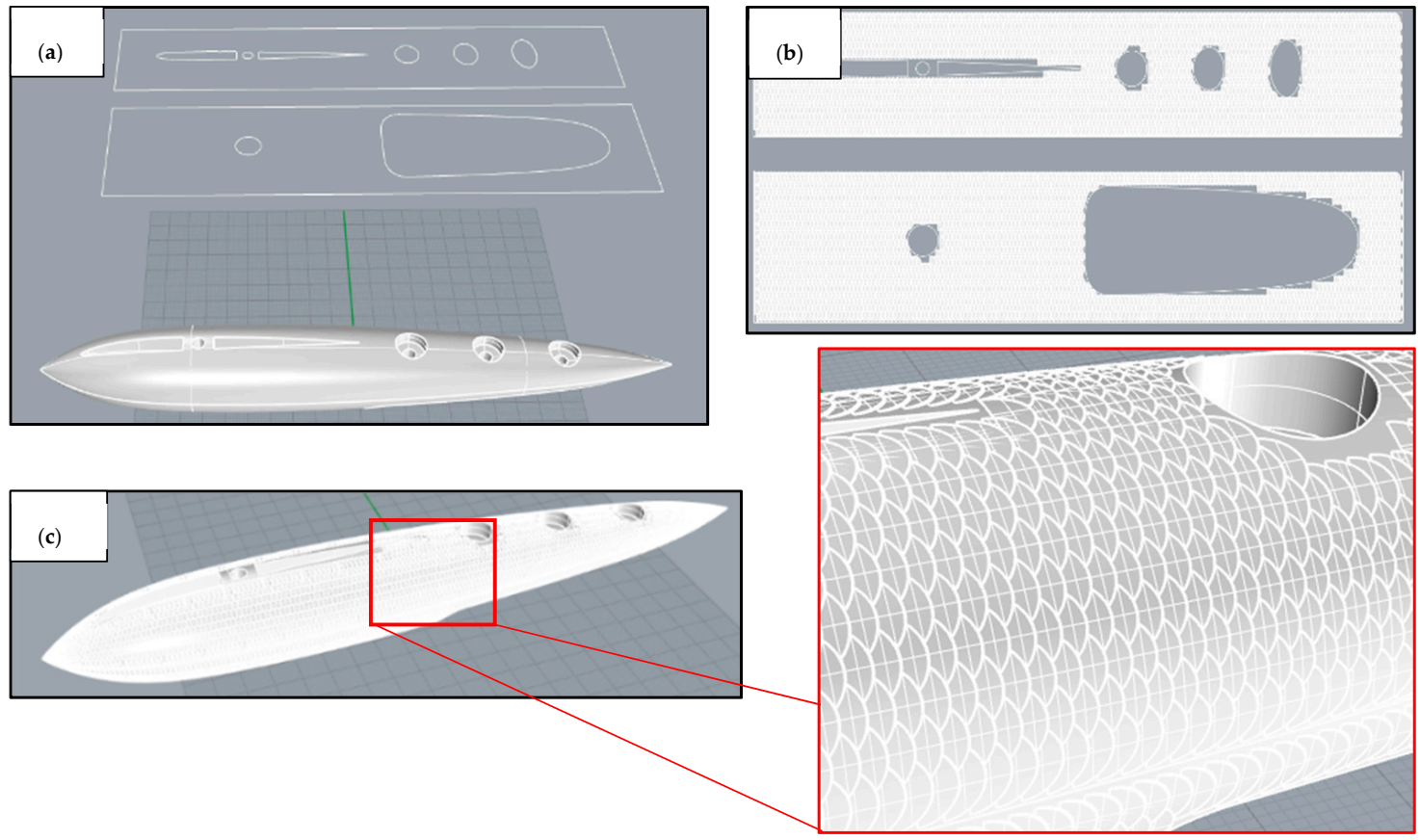

Figure A6. Scale application on bulb external surface; (a) reference half-surfaces, (b) prepared planar scale pattern for "flow along surface", (c) applied scales. The overall longitudinal length of the component is $290 \mathrm{~mm}$.
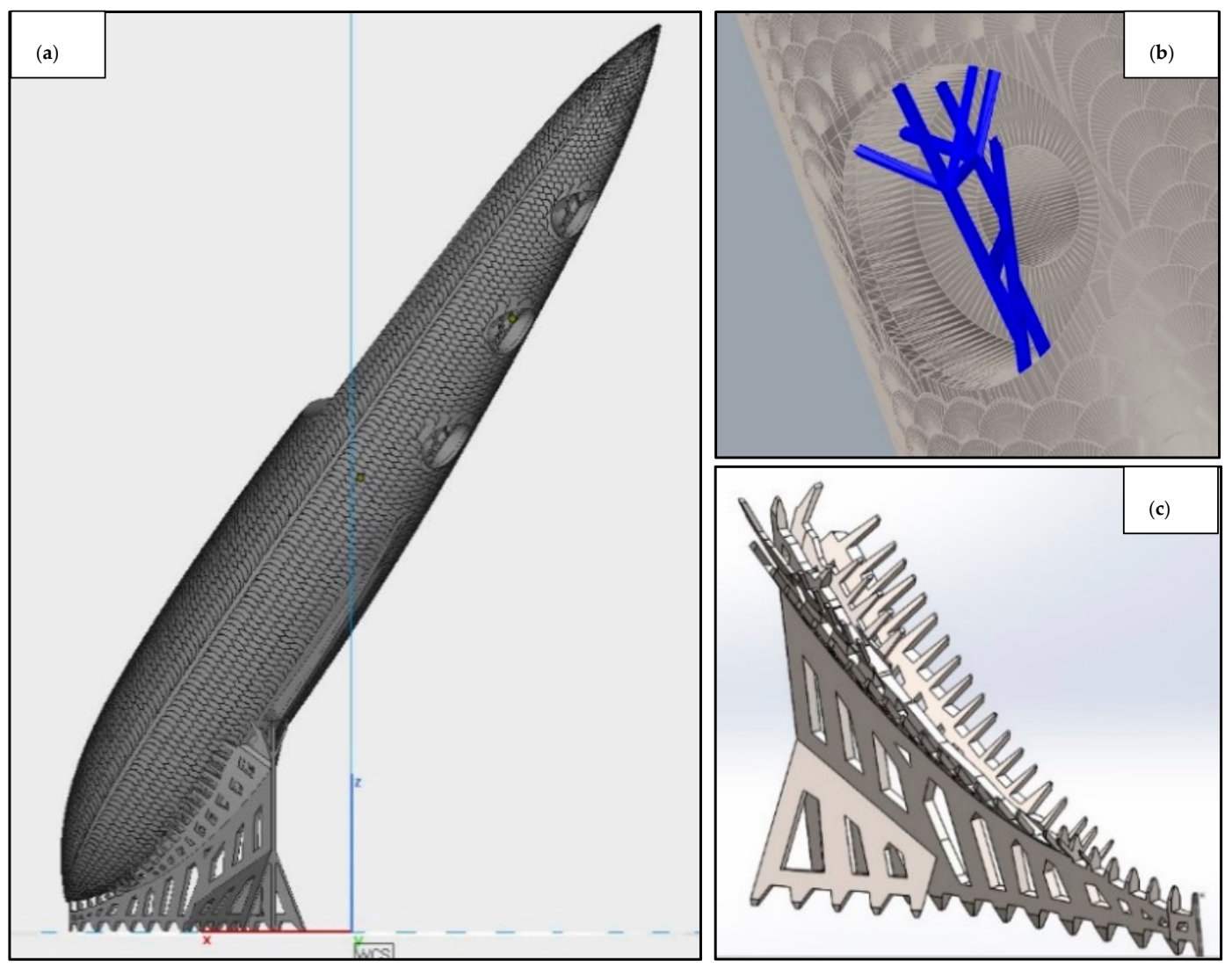

Figure A7. (a) Oriented and supported scales-equipped bulb model, (b) detail on bolted connection holes support structures and (c) isolated main support structure geometry. The overall longitudinal length of the component is $290 \mathrm{~mm}$. 


\section{References}

1. Ramirez-Peña, M.; Sotano, A.J.S.; Pérez-Fernandez, V.; Abad, F.J.; Batista, M. Achieving a sustainable shipbuilding supply chain under I4.0 perspective. J. Clean. Prod. 2020, 244, 118789. [CrossRef]

2. University of Maine. Available online: https://composites.umaine.edu/3dirigo-the-worlds-largest-3d-printed-boat/ (accessed on 7 May 2020).

3. Braghin, F. Tecnologie Free-form per la Realizzazione di Componenti Nautici Tramite Fiber Placement. In NAUTICA +++ I Additive Manufacturing in campo Navale e Nautico I Arianna Bionda e Andrea Ratti; Edizioni Poli.design: Milano, Italy, 2017; ISBN 978-88-95651-11-8.

4. Tecniche Nuove Spa, Mini 650. Available online: https:/ / www.plastix.it/mini-650-ocore-stampa-3d/ (accessed on 29 April 2020).

5. Cevola, D. Fabbricazione Additiva nel Comparto Nautico: Nuovi Scenari e Prospettive. In NAUTICA +++. Additive Manufacturing in Campo Navale e Nautico I Arianna Bionda e Andrea Ratti; Edizioni Poli.design: Milano, Italy, 2017; ISBN 978-88-95651-11-8.

6. Nemani, A.V.; Ghaffari, M.; Nasiri, A. Comparison of microstructural characteristics and mechanical properties of shipbuilding steel plates fabricated by conventional rolling versus wire arc additive manufacturing. Addit. Manuf. 2020, 32, 101086. [CrossRef]

7. Horgar, A.; Fostervoll, H.; Nyhus, B.; Ren, X.; Eriksson, M.; Akselsen, O. Additive manufacturing using WAAM with AA5183 wire. J. Mater. Process. Technol. 2018, 259, 68-74. [CrossRef]

8. Torims, T.; Pikurs, G.; Ratkus, A.; Logins, A.; Vilcāns, J.; Sklariks, S. Development of Technological Equipment to Laboratory Test In-situ Laser Cladding for Marine Engine Crankshaft Renovation. Procedia Eng. 2015, 100, 559-568. [CrossRef]

9. Korsmik, R.S.; Rodionov, A.A.; Korshunov, V.A.; Ponomarev, D.A.; Prosychev, I.S.; Promakhov, V.V. Topological optimization and manufacturing of vessel propeller via LMD-method. Mater. Today Proc. 2020, 30, 538-544. [CrossRef]

10. Liravi, M.; Pakzad, H.; Moosavi, A.; Nouri-Borujerdi, A. A comprehensive review on recent advances in superhydrophobic surfaces and their applications for drag reduction. Prog. Org. Coat. 2020, 140, 105537. [CrossRef]

11. Aboulkhair, N.T.; Simonelli, M.; Parry, L.; Ashcroft, I.; Tuck, C.; Hague, R. 3D printing of Aluminium alloys: Additive Manufacturing of Aluminium alloys using selective laser melting. Prog. Mater. Sci. 2019, 106, 100578. [CrossRef]

12. Park, S.H.; Lee, I. Optimization of drag reduction effect of air lubrication for a tanker model. Int. J. Nav. Archit. Ocean Eng. 2018, 10, 427-438. [CrossRef]

13. Pujals, G.; Depardon, S.; Cossu, C.; Pujals, G.; Depardon, S.; Cossu, C. Drag reduction of a 3D bluff body using coherent streamwise streaks. Exp. Fluids 2010, 5, 1085-1094. [CrossRef]

14. Fu, Y.F.; Yuan, C.Q.; Bai, X.Q. Marine drag reduction of shark skin inspired riblet surfaces. Biosurface Biotribology 2017, 3, 11-24. [CrossRef]

15. Ibrahim, M.D.; Amran, S.N.A.; Yunos, Y.S.; Rahman, M.R.A.; Mohtar, M.Z.; Wong, L.K.; Zulkharnain, A. The Study of Drag Reduction on Ships Inspired by Simplified Shark Skin Imitation. Appl. Bionics Biomech. 2018, 2018, 1-11. [CrossRef] [PubMed]

16. Ran, W.; Zare, A.; Jovanović, M.R. Model-Based Design of Riblets for Turbulent Drag Reduction. February 2020. Available online: http:/ / arxiv.org/abs/2002.01671 (accessed on 5 June 2020).

17. Song, X.; Zhang, M. Turbulent Drag Reduction Characteristics of Bionic Nonsmooth Surfaces with Jets. Appl. Sci. 2019, 9, 5070. [CrossRef]

18. Bai, J.; Meng, X.; Ji, C.; Liang, Y. Drag reduction characteristics and flow field analysis of textured surface. Friction 2016, 4, 165-175. [CrossRef]

19. Hu, H.; Tamai, M.; Murphy, J.T. Flexible-Membrane Airfoils at Low Reynolds Numbers. J. Aircr. 2008, 45, 1767-1778. [CrossRef]

20. Banks, J.; Giovannetti, L.M.; Taylor, J.; Turnock, S. Assessing Human-Fluid-Structure Interaction for the International Moth Procedia Eng. 2016, 147, 311-316. [CrossRef]

21. Giovannetti, L.M.; Banks, J.; Ledri, M.; Turnock, S.; Boyd, S. Toward the development of a hydrofoil tailored to passively reduce its lift response to fluid load. Ocean Eng. 2018, 167, 1-10. [CrossRef]

22. International Sailing Federation. International Moth Class Rules. 1 May 2017. Available online: http:/ / www.moth-sailing.org/ history/rules-and-documents / (accessed on 1 February 2020).

23. Pereira, J.C.; Gil, E.; Solaberrieta, L.; Sebastián, M.S.; Bilbao, Y.; Rodríguez, P.P. Comparison of AlSi7Mg0.6 alloy obtained by selective laser melting and investment casting processes: Microstructure and mechanical properties in as-built/as-cast and heat-treated conditions. Mater. Sci. Eng. A 2020, 778, 139124. [CrossRef]

24. Muthuramalingam, M.; Villemin, L.S.; Bruecker, C. Streak formation in flow over biomimetic fish scale arrays. J. Exp. Biol. 2019, 222. [CrossRef]

25. Rao, H.; Giet, S.; Yang, K.; Wu, X.; Davies, C. The influence of processing parameters on aluminium alloy A357 manufactured by Selective Laser Melting. Mater. Des. 2016, 109, 334-346. [CrossRef]

26. Rao, J.H.; Zhang, Y.; Fang, X.; Chen, Y.; Wu, X.; Davies, C.H. The origins for tensile properties of selective laser melted aluminium alloy A357. Addit. Manuf. 2017, 17, 113-122. [CrossRef]

27. Trevisan, F.; Calignano, F.; Lorusso, M.; Pakkanen, J.; Ambrosio, E.P.; Lombardi, M.; Pavese, M.; Manfredi, D.; Fino, P. Effects of Heat Treatments on A357 Alloy Produced by Selective Laser Melting. In Proceedings of the World PM 2016 Congress Exhibition: European Powder Metallurgy Association, Hamburg, Germany, 9-13 October 2016; pp. 1-7.

28. Aversa, A.; Lorusso, M.; Trevisan, F.; Ambrosio, E.P.; Calignano, F.; Manfredi, D.G.; Biamino, S.; Fino, P.; Lombardi, M.; Pavese, M. Effect of Process and Post-Process Conditions on the Mechanical Properties of an A357 Alloy Produced via Laser Powder Bed Fusion. Metals 2017, 7, 68. [CrossRef] 
29. Grande, A.M.; Cacace, A.; Demir, A.G.; Sala, G. Fracture and fatigue behaviour of AlSi7Mg0. 6 produced by Selective Laser Melting: Effects of thermal-treatments. In Proceedings of the 25th Conference of the Italian Association of Aeronautics and Astronautics (AIDAA 2019) AIDAA, Rome, Italy, 9-12 September 2019; pp. 1138-1144.

30. Sorci, R.; Tassa, O.; Colaneri, A.; Astri, A.; Mirabile, D.; Iwnicki, S.; Demir, A.G. Design of an Innovative Oxide Dispersion Strengthened Al Alloy for Selective Laser Melting to Produce Lighter Components for the Railway Sector. J. Mater. Eng. Perform. 2021, 30, 1-11. [CrossRef]

31. Garavaglia, M.; Demir, A.G.; Zarini, S.; Victor, B.M.; Previtali, B. Fiber laser welding of AA 5754 in the double lap-joint configuration: Process development, mechanical characterization, and monitoring. Int. J. Adv. Manuf. Technol. 2020, 111, 1643-1657. [CrossRef]

32. Mäkikangas, J.; Rautio, T.; Mustakangas, A.; Mäntyjärvi, K. Laser welding of AlSi10Mg aluminium-based alloy produced by Selective Laser Melting (SLM). Procedia Manuf. 2019, 36, 88-94. [CrossRef] 